\title{
The Role of Presynaptic Calcium in Short-Term Enhancement at the Hippocampal Mossy Fiber Synapse
}

\author{
Wade G. Regehr, Kerry R. Delaney, ${ }^{a}$ and David W. Tank \\ AT\&T Bell Laboratories, Murray Hill, New Jersey 07974
}

The mossy fiber synapse between dentate granule cells and CA3 pyramidal cells in the guinea pig hippocampus shows a robust short-term synaptic enhancement. We have simultaneously measured presynaptic residual free calcium $\left(\left[\mathrm{Ca}^{2+}\right]_{i}\right)$ and postsynaptic field potentials at this synapse to examine the role of $\left[\mathrm{Ca}^{2+}\right]_{i}$ in this enhancement. Single action potentials produced an increase in $\left[\mathrm{Ca}^{2+}\right]_{i}$ of 10-50 nM that decayed to resting levels with a time constant of about 1 sec. Trains of action potentials produced larger $\left[\mathrm{Ca}^{2+}\right]_{i}$ increases that returned more slowly to resting levels.

Following the onset of moderate frequency stimulus trains $(0.1-5 \mathrm{~Hz})$, synaptic transmission and $\left[\mathrm{Ca}^{2+}\right]_{i}$ both increased and eventually plateaued. During the steady-state phase a linear relationship between $\left[\mathrm{Ca}^{2+}\right]_{i}$ and synaptic enhancement was observed. During the initial buildup, however, $\left[\mathrm{Ca}^{2+}\right]_{\text {; }}$ rose more rapidly than synaptic enhancement. Similarly, during the decay phase immediately following termination of a

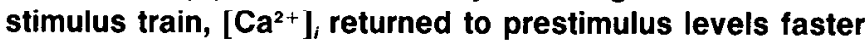
than synaptic enhancement.

High concentrations of the calcium buffer EGTA in the presynaptic terminal slowed the buildup and decay of both $\left[\mathrm{Ca}^{2+}\right]_{i}$ and synaptic enhancement produced by stimulus trains. Under these conditions, the time course of $\left[\mathrm{Ca}^{2+}\right]_{i}$ and synaptic enhancement were well matched. This suggests that, despite the differences in kinetic rates observed for normal buffering conditions, increases in $\left[\mathrm{Ca}^{2+}\right]_{i}$ play a causal role in short-term enhancement. An increase in $\left[\mathrm{Ca}^{2+}\right]_{i}$ of 10-30 nm produced a twofold enhancement.

We propose a simple kinetic model to explain these results. The model assumes that synaptic enhancement is controlled by a $\mathrm{Ca}$-dependent first-order reaction. According to this scheme, a change in $\left[\mathrm{Ca}^{2+}\right]$, alters neurotransmitter release, but the slow kinetics of the underlying reaction introduces a temporal filter, producing a delay in the change in synaptic enhancement.

[Key words: synaptic facilitation, transmitter release, fura2, calcium dynamics, hippocampal mossy fibers]

Synapses are dynamically modified to reflect their history of use (Zengel et al., 1980; Kretz et al., 1982; McNaughton, 1982; Atwood and Wojtowicz, 1986; Magleby, 1987; Griffith, 1990).

Received Dec. 21, 1992; revised June 29, 1993; accepted July 6, 1993.

We thank R. S. Zucker for comments on the manuscript. W.G.R. was the recipient of an MRC Canada fellowship.

Correspondence should be addressed to Wade G. Regehr, Department of Neurobiology, Harvard Medical School, 220 Longwood Ave., Boston, MA 02115.

a Present address: Department of Biology, Simon Fraser University, British Columbia, Canada.

Copyright (C) 1994 Society for Neuroscience $0270-6474 / 94 / 140523-15 \$ 05.00 / 0$
Normal variations in the firing pattern of neurons produce significant transient changes in synaptic strength, and such changes undoubtedly contribute to the computations performed in nervous systcms. In the mammalian CNS, the magnitude of this short-term synaptic enhancement can be large at stimulus frequencies similar to the rates of activity observed in single-unit recordings of presynaptic cells in vivo. It is thus a candidate for the biophysical basis for some forms of short-term memory. In contrast to the considerable effort devoted to discovering the molecular mechanisms responsible for long-term potentiation, the examination of short-term enhancement in the mammalian CNS has primarily been restricted to phenomenological characterization. The biophysical processes responsible for such alterations are poorly understood.

Short-term synaptic enhancement has been most thoroughly characterized at invertebrate synapses and at the neuromuscular junction in vertebrates (Atwood and Wojtowicz, 1986; Magleby, 1987). High-frequency stimulus trains enhance release both during and after stimulation. Based upon differences in time course and pharmacology, this enhancement is separated into four components: posttetanic potentiation (PTP), augmentation, facilitation component $F 2$, and facilitation component $F 1$, with time constants of decay of 30-90 sec, 5-10 sec, 200-500 msec, and $20-100 \mathrm{msec}$, respectively. Quantal analysis indicates that these forms of enhancement are presynaptic in origin.

Presynaptic free calcium has long been implicated in shortterm enhancement (Katz and Miledi, 1968; Charlton et al., 1982; Connor et al., 1986; Delaney et al., 1989; Swandula et al., 1991; Zucker et al., 1991). In this vicw, calcium plays a dual role: in addition to triggering the vesicle fusion underlying neurotransmitter release, calcium can act on a slower time scale to alter the probability of vesicle fusion. The essential role of calcium in synaptic transmission has been known since the experiments of Katz and Miledi (1967). Action potentials open voltage-gated calcium channels strategically located near release sites (Roberts et al., 1990; Robilaille et al., 1990; Cohen et al., 1991), calcium enters the presynaptic terminal, and initiates vesicle fusion. One popular hypothesis has been that the residual calcium that remains from previous action potentials sums with the calcium influx produced by subsequent action potentials to enhance release (Katz and Miledi, 1968; Zucker, 1988).

The involvement of residual calcium in PTP and augmentation, the slower components of short-term enhancement, has recently been demonstrated at the crayfish neuromuscular junction by dircet comparison of presynaptic calcium and enhancement (Delaney et al., 1989; Delaney and Tank, 1994). An approximately linear relationship between increases in $\left[\mathrm{Ca}^{2+}\right]_{i}$ and synaptic enhancement was observed, and experiments suggested that increased $\left[\mathrm{Ca}^{2+}\right]_{i}$ caused the increases in the probability of 
release during augmentation and PTP. While it is thought that for fast synapses it takes more than $50 \mu \mathrm{M}$ to trigger fusion (Simon and Llinas, 1985), for the crayfish neuromuscular junction a $\left[\mathrm{Ca}^{2+}\right]_{i}$ increase of just $600 \mathrm{~nm}$ enhanced release severalfold. The results are not in accord with the residual calcium hypothesis described above where release is en hanced by simple elevation of peak calcium level reached following an action potential (see discussion in Delaney et al., 1989). Rather, it appears that the residual calcium modulates the probability of relcase through a rapid biochemical process. Thus, the time courses of augmentation and PTP at this synapse are dictated

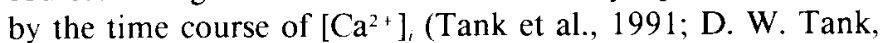
K. R. Delaney, and W. G. Regehr, unpublished observations).

Here we examine the role of $\left[\mathrm{Ca}^{2+}\right]_{i}$ in short-term use-dependent enhancement at a mammalian central synapse, the hippocampal mossy fiber synapse. The mossy fibers originate from dentate granule cells and make en passant synaptic connections on the proximal apical dendrite of CA3 pyramidal cells (Amaral, 1979; Claiborne et al., 1986). In addition to showing a pronounced short-term enhancement (Griffith, 1990), the large presynaptic terminals associated with this pathway are well suited to free calcium ion imaging methods (Regehr and Tank, 1991a,c). In a previous study we simultaneously measured presynaptic calcium and postsynaptic field potentials and determined that the maintenance of long-term potentiation at this synapse is not produced by persistent increases in $\left[\mathrm{Ca}^{2+}\right]_{l}$ (Regehr and Tank, 1991a). In the present study we use a similar approach to test the hypothesis that increases in $\left[\mathrm{Ca}^{2}{ }^{2}\right]_{i}$ produce short-term synaptic enhancement on the time scales of augmentation and PTP during and after elevated firing levels. We find that increases in $\left[\mathrm{Ca}^{2+}\right]$ are correlated with increased enhancement and provide evidence that the relationship is causal. However, changes in synaptic strength are found to lag changes in $\left[\mathrm{Ca}^{2+}\right]_{i}$ at mossy fiber synapses, in contrast to the crayfish neuromuscular junction where such a lag was not apparent. A model is proposed in which this temporal mismatch is accounted for by the slow kinetics of a first-order calcium-dependent reaction, where the product of this reaction produces the synaptic enhancement.

Preliminary reports of these findings have been published (Delaney et al., 1991; Regehr and Tank, 1991 b; Regehr et al., 1992).

\section{Materials and Methods}

Brain slice preparation and electrophysiology. The results presented in this article summarize experiments from 80 transverse hippocampal slices from 45 guinea pigs (150-250 gm). Slice preparation and maintenance followed previously described procedures (Regehr et al., 1991a,c, 1992b). Unless otherwise indicated, the artificial cerebral spinal fluid (ACSF) contained (in mM) $124 \mathrm{NaCl}, 3 \mathrm{KCl}, 2.5 \mathrm{CaCl}_{2}, 4 \mathrm{MgCl}_{2}, 26$ $\mathrm{NaHCO}_{3}, 10$ D-glucose, 50-100 $\mu \mathrm{M}$ DL-2-aminophosphono-5-valeric acid (AP5) (Sigma), and $50 \mu \mathrm{M}$ picrotoxin (Sigma). The NMDA receptor antagonist AP5 was present to prevent possible potentiation of associational responses, and picrotoxin was present to prevent $\mathrm{GABA}_{\mathrm{A}}$ inhibition from contaminating the extraccllular postsynaptic potential (PSP).

The monosynaptic connection strength was measured using the procedure introduced in Regehr and Tank (1991a). The key to successful measurement of a monosynaptic PSP was to use the fura-2 fluorescence of labeled mossy fibers to guide electrode placement. An extracellular stimulus electrode was placed near the fura-2 loading site, and a recording electrode was positioned near the imaged terminals, $500-1000$ $\mu \mathrm{m}$ from the stimulus electrodes. All experiments satisfied our criteria for the postsynaptic potential having little contamination from activation of fibers of passage other than mossy fibers: (1) the magnitude of the presynaptic volley and the extracellular postsynaptic potential dropped off rapidly when the recording electrode was moved from the mossy fiber tract, (2) the high concentration of divalent ions raised the threshold for firing an action potential sufficiently to prevent a population spike from occurring, and (3) the contribution of disynaptic responses was minimized by placing the recording electrode near the stimulus electrode and recording the initial slope of the PSP. No detectable change in the presynaptic volley amplitude for test pulses occurred during the course of an experiment. Test pulses were $0.2 \mathrm{~Hz}$ except as noted in the text. The initial slope of the unfacilitated PSP was $1-4 \mathrm{mV} / \mathrm{msec}$ at $32-34^{\circ} \mathrm{C}, 1.5-5 \mathrm{mV} / \mathrm{msec}$ at $25-27^{\circ} \mathrm{C}$, and 0.2 $0.6 \mathrm{mV} / \mathrm{msec}$ at $32-34^{\circ} \mathrm{C}$ in the presence of elevated levels of internal EGTA.

Microfluorimetry of calcium ion concentration. Mossy fiber terminals were labeled with fura-2 AM using a localized perfusion method dcscribed in detail elsewhere (Regehr and Tank, 1991a,c). The labeling solution was prepared by dissolving $50 \mu \mathrm{g}$ of fura-2 AM (Molecular Probes, Eugene, OR) in $20 \mu \mathrm{l} 75 \%$ dimethyl sulfoxide (DMSO) $/ 25 \%$ pluronic acid, and adding this to $500 \mu \mathrm{l}$ of ACSF. The solution was vortexed for $1 \mathrm{~min}$, and filtered $(0.2 \mu \mathrm{m})$. Fura- 2 ratios were measured using a high-performance cooled CCD-based imaging system as described previously (Regehr and Tank, 1992). Stimulus-evoked $\left[\mathrm{Ca}^{2+}\right]$ accumulations were not reduced by the $\alpha$-amino-3-hydroxy-5-methylisoxazole acid (AMPA) receptor antagonist 6-cyano-7-nitroquinoxaline2,3-dione (CNQX), and each presynaptic terminal had a discrete threshold for extracellular stimulation (Regehr and Tank, 1991a).

Changes in calcium concentration in individual mossy fiber terminals were computed from the fura-2 fluorescence produced by $340 \mathrm{~nm}$ and $380 \mathrm{~nm}$ excitation, using the ratio method and Equation 1 (taken from Grynkiewicz et al., 1985):

$$
\left[\mathrm{Ca}^{2+}\right]_{i}=\frac{S_{/ 2}}{S_{t, 2}} K_{,} \frac{\left(R-R_{\min }\right)}{\left(R_{\max }-R\right)},
$$

where $K_{\mathrm{D}}$ is the dissociation constant of fura-2 (200 nм for these experimental conditions), $R$ is the ratio of fura- 2 fluorescence produced by $340 \mathrm{nM}$ and $380 \mathrm{~nm}$ excitation, $R_{\min }$ is the value in the presence of $0\left[\mathrm{Ca}^{2+}\right]_{1}, R_{\max }$ is in the presence of saturating $\left[\mathrm{Ca}^{2+}\right]_{l}$, and $S_{t 2} / S_{b 2}$ is the ratio of the intensity of fluorescence excited by $380 \mathrm{~nm}$ illumination for a solution containing no calcium divided by that for a solution containing saturating calcium. $K_{D}, R_{\max }, R_{\min }$, and $S_{t_{2}} / S_{b 2}$ were determined from in vitro calibrations, and a viscosity correction factor of 0.7 was used for this calibration (Poenie et al., 1986; Regehr and Tank, 1992). It was not possible to perform a calibration within the cell since calcium ionophores were not effective in making mossy fiber terminals permeable to calcium (presumably the ionophores do not have access to regions within the slice). Since the properties of fura-2 depend upon the local environment, they are influenced not only by the viscosity, but by binding of the dye within the cell (Konishi et al., 1988). This problem is particularly acute for resting $\left[\mathrm{Ca}^{2+}\right]$, levels that are extremely sensitive to $R_{\min }$ [proportional to $\left(R-R_{\min }\right)$ ], and therefore we do not report resting calcium (see Harkins et al., 1993, for an example of determination of resting calcium). $\Delta\left[\mathrm{Ca}^{2+}\right]$, was reported, however, and as shown by Equation 3, even for small calcium concentrations $\Delta\left[\mathrm{Ca}^{2+}\right]$, does not depend upon $R_{\min }$. It must be remembered that the absolute values of $\Delta\left[\mathrm{Ca}^{2+}\right]_{\text {given }}$ in Results are sensitive to $K_{i j}, S_{i 2} / S_{b_{2}}$, and $R_{\max }$, and differences between the in vitro calibration and the properties of fura-2 within a cell will produce an error in our estimate of $\Delta\left[\mathrm{Ca}^{2+}\right]$.

Calculations were performed from the average fluorescence measured in a region of interest centered over individual presynaptic terminals. Aggregate fura-2 fluorescence ratio of unresolved terminals was determined from $340 \mathrm{~nm}$ and $380 \mathrm{~nm}$ image pairs acquired at $10 \mathrm{~Hz}$ with the camera operating in frame transfer mode unless otherwise noted. Fluorescence from an area of approximately $50 \mu \mathrm{m} \times 50 \mu \mathrm{m}$ was used for these aggregate measurements.

We feel that the fura- 2 transients we recorded provided a good measure of the time course of calcium in mossy fiber presynaptic terminals at times greater than $100 \mathrm{msec}$ following a calcium influx. First, because the terminals are only about $5 \mu \mathrm{m}$ in diameter, large spatial gradients will be dissipated by diffusion within $100 \mathrm{msec}$ of a calcium influx. Second, we used fura-2 at sufficiently low concentrations to cause insignificant changes in the Ca kinetics. If higher fura- 2 concentrations are used such that the buffer capacity of fura- 2 is high compared to that of the intrinsic buffer, then calcium increases would be made smaller and $\mathrm{Ca}$ kinetics slower. We avoided this difficulty in part by using highnumerical-aperture objectives to remove the need for intense labeling. 
In addition, we checked for the possibility of excessive loading by comparing kinetics for terminals labeled in the usual way to the kinetics in terminals labeled for one-fourth the usual time. The labeling was correspondingly less bright, and the signal-to-noise ratio was poor, but the kinetics were unaltered. Third, the temperature dependence of the properties of fura-2 did not affect the determination of the time constant of calcium decay since calcium concentrations used to determine time constants of decay were well below the dissociation constant of fura- 2 . Within this range there is a linear relationship between the change in fura- 2 fluorescence and the calcium concentration, and fura- 2 ratio kinetics are the same as the calcium concentration kinetics. Fourth, compartmentalization did not appear to be a problem. When using fura-2 AM, compartmentalization within cellular structures is often observed. This leads to erroneous estimates of the free calcium level and is often reflected in an apparent increase in free calcium levels with time as the compartmentalization becomes more severe. In these studies at locations distant from the loading site, resting levels of fura-2 ratio were stable for many hours and compartmentalization was not apparent. This suggested that although fura-2 AM was used in these studies, fura- 2 at the recording sites behaves very much like the free acid form. This may be because the recording site is not exposed to DMSO and deesterification occurs before the dye has had a chance to diffuse very far.

When calcium concentrations are low, a linear relationship exists between calcium and fura ratio, and the time course of ratio transients closely approximates the time course of calcium transients. Assuming $R \ll R_{\max }$ (a condition satisfied when $\left[\mathrm{Ca}^{2+}\right]_{i}$ is below the $K_{D}$ of fura2), Equation 5 of Grynkiewicz et al., 1985, can be approximated to second order in $R / R_{\max }$ by

$$
\left[C a^{2+}\right]_{l} \approx \frac{S_{f 2}}{S_{h 2}} K_{l} \frac{\left(R-R_{\min }\right)}{R_{\max }}\left(1+\frac{R}{R_{\max }}\right) .
$$

Provided $R / R_{\text {max }} \ll 1$, there is an approximately linear relationship between $\Delta\left[\mathrm{Ca}^{2+}\right]_{\text {, }}$ and $\Delta R$,

$$
\Delta\left[\mathrm{Ca}^{2+}\right]=\frac{S_{12}}{S_{b, 2}} K_{b} \frac{\Delta R}{R_{\max }}
$$

and the deviation from linearity in $\Delta R$ is given by $R / R_{\max }$ (see Eq. 2). This holds when $\left[\mathrm{Ca}^{2+}\right]$, is small, but is not valid for large $\left[\mathrm{Ca}^{2+}\right]$. When $\left[\mathrm{Ca}^{2+}\right]_{l}=K_{l}$, the deviation from linearity is given by the expression

$$
\frac{R}{R_{\max }}=\left(1+\frac{S_{f 2}}{S_{h, 2}}\right)^{\prime}\left(1+\frac{S_{j z} R_{\min }}{S_{h 2} R_{\max }}\right) .
$$

For our experimental conditions, when $\left[\mathrm{Ca}^{2+}\right]_{i}=K_{n}, R / R_{\max }$ is about 0.07 (i.e., a deviation of about $7 \%$ from a linear relationship exists). Thus, provided calcium levels are below the dissociation constant of fura, the deviation from linearity is small, and the time course of calcium transients measured from the decay of the ratio is close to the actual calcium decay. For example, if calcium decays exponentially with a time constant of $10 \mathrm{sec}$ from $200 \mathrm{~nm}$ to $50 \mathrm{~nm}$, the time constant of decay determined by fitting an exponential to the decay of fura- 2 ratio is 10.2 sec, an overestimate of about $2 \%$.

Loading with EGTA and EDTA. In experiments where intracellular calcium buffering was elevated, the mossy fiber tract was first labeled with fura- 2 by localized perfusion. Slices were then incubated in ACSF containing EGTA-AM or EDTA-AM using a loading procedure similar to that described for BAPTA-AM (Neisen et al., 1991). EDTA-AM or EGTA-AM stock solutions ( $10 \mathrm{~mm}$ ) were prepared in DMSO and stored at $-30^{\circ} \mathrm{C}$. Stock solutions were removed from the freezer on the day of the experiment and added to ACSF to give a loading solution containing $0.5 \%$ DMSO and $50 \mu \mathrm{m}$ of cither EDTA-AM or EGTA-AM. Two hippocampal slices were then transferred to a container with $2 \mathrm{ml}$ of continuously oxygenated loading solution. Slices were loaded for $30 \mathrm{~min}$ and then transferred to a holding chamber containing normal oxygenated slice saline for 30-60 min prior to imaging experiments. Incubation in ACSF containing 0.5\% DMSO alone did not alter the kinetics of calcium or synaptic enhancement. In other experiments, a baseline response was measured in the presence of a perfusate containing $0.2 \%$ DMSO alone. Then the perfusate was changed to one containing $0.2 \%$ DMSO and EGTA-AM and the response of calcium and PSP were monitored during loading. EGTA and EDTA were well suited to slow the rise and fall of calcium without completely blocking synaptic transmission, unlike a fast buffer such as BAPTA, which would have blocked synaptic transmission (Adler et al., 1991; Delaney and Tank, 1994).
Kinetic modeling of a calcium driven reaction. Numerical simulations of the kinetic model presented in the text were performed on a microcomputer. A single compartment was assumed and the differential equations describing the reaction were integrated by the Euler integration method with a time step of $0.1 \mathrm{msec}$. A test of shorter integration time steps produced no significant change in the results. Where possible, numerical results were compared to analytical solutions. Initial conditions are specified in the text.

\section{Results}

The buildup and decay of calcium in mossy fiber presynaptic terminals

Changes in presynaptic free calcium concentrations in mossy fiber terminals were determined following fura- 2 loading by local perfusion of the mossy fiber tract (Regehr and Tank, 1991c). After allowing $1-4 \mathrm{hr}$ for fura-2 to diffuse down the axon and fill distant terminals, stimulus and recording electrodes were positioned, as shown in Figure 1, using fura-2 fluorescence as a guide. A high-power objective $(40 \times$ or $100 \times)$ was then used to image presynaptic terminals in stratum lucidum well away from the initial perfusion site.

As shown in Figure $2 A$, single action potentials produced $\left[\mathrm{Ca}^{2+}\right]_{i}$ increases in individual mossy fiber terminals of $39 \pm 13$ $\mathrm{nM}( \pm \mathrm{SD}, n=10$, range $=21-64 \mathrm{~nm})$ in $4 \mathrm{~mm}$ extcrnal calcium, and $14 \pm 7 \mathrm{nM}( \pm \mathrm{SD}, n=4$, range $=8-21 \mathrm{nM})$ in $2.5 \mathrm{~mm}$ external calcium. The return of $\left[\mathrm{Ca}^{2+}\right]_{i}$ to resting levels was well approximated by an exponential decay with a time constant of $1.1 \pm 0.4 \mathrm{sec}( \pm \mathrm{SD}, n=14$, range $=650-2000 \mathrm{msec})$. In some cases it was possible to obtain good signal-to-noise ratios for $\left[\mathrm{Ca}^{2+}\right]_{i}$ changes in individual terminals without signal averaging, but Figure $2 A$ is representative of the more typical case in which an estimate of the increase of $\left[\mathrm{Ca}^{2+}\right]_{i}$ produced by single action potentials is possible but characterization of the exact time course is compromised by the poor signal-to-noise ratio.

To better determine the kinetics of $\left[\mathrm{Ca}^{2+}\right]_{i}$ transients, the summed fura- 2 fluorescence from many terminals was measured. Based upon fluorescence intensity we estimate that hundreds of mossy fiber terminals contribute to these signals. Figure $2 B$ shows the fura- 2 ratio change in a large number of terminals produced by a single stimulus. The signal-to-noise ratio was greatly improved over similar measurements made from individual presynaptic terminals. Given an average terminal diameter of about $3 \mu \mathrm{m}$, an interterminal distance of $135 \mu \mathrm{m}$, and an axonal diameter of $0.2 \mu \mathrm{m}$, we estimate that presynaptic terminals contribute $75 \%$ of the total fura-2 fluorescence (Claiborne et al., 1986). It is, however, not possible to use this spatially averaged fluorescence to determine $\left[\mathrm{Ca}^{2+}\right]_{i}$ change per activated terminal since it is not known to what extent activated terminals, nonactivated terminals, and axons contribute to the total fluorescence.

We then tested the hypothesis that changes in the aggregate fura-2 fluorescence can be used to determine the time course of calcium transients in individual terminals. In Figure $2 \mathrm{C}$ the calcium transients in individual terminals and the aggregate ratio transients are plotted on the same graph. Both transients were produced by 10 action potentials delivered at $100 \mathrm{~Hz}$. The similarity of the time courses suggests that measuring changes in the aggregate fura-2 fluorescence ratio is an appropriate way to determine the time course of calcium transients in individual terminals (see Materials and Methods).

These measurements of calcium transients have a direct bearing on attempts to compare $\Delta\left[\mathrm{Ca}^{2+}\right]_{i}$ to enhanced release during 


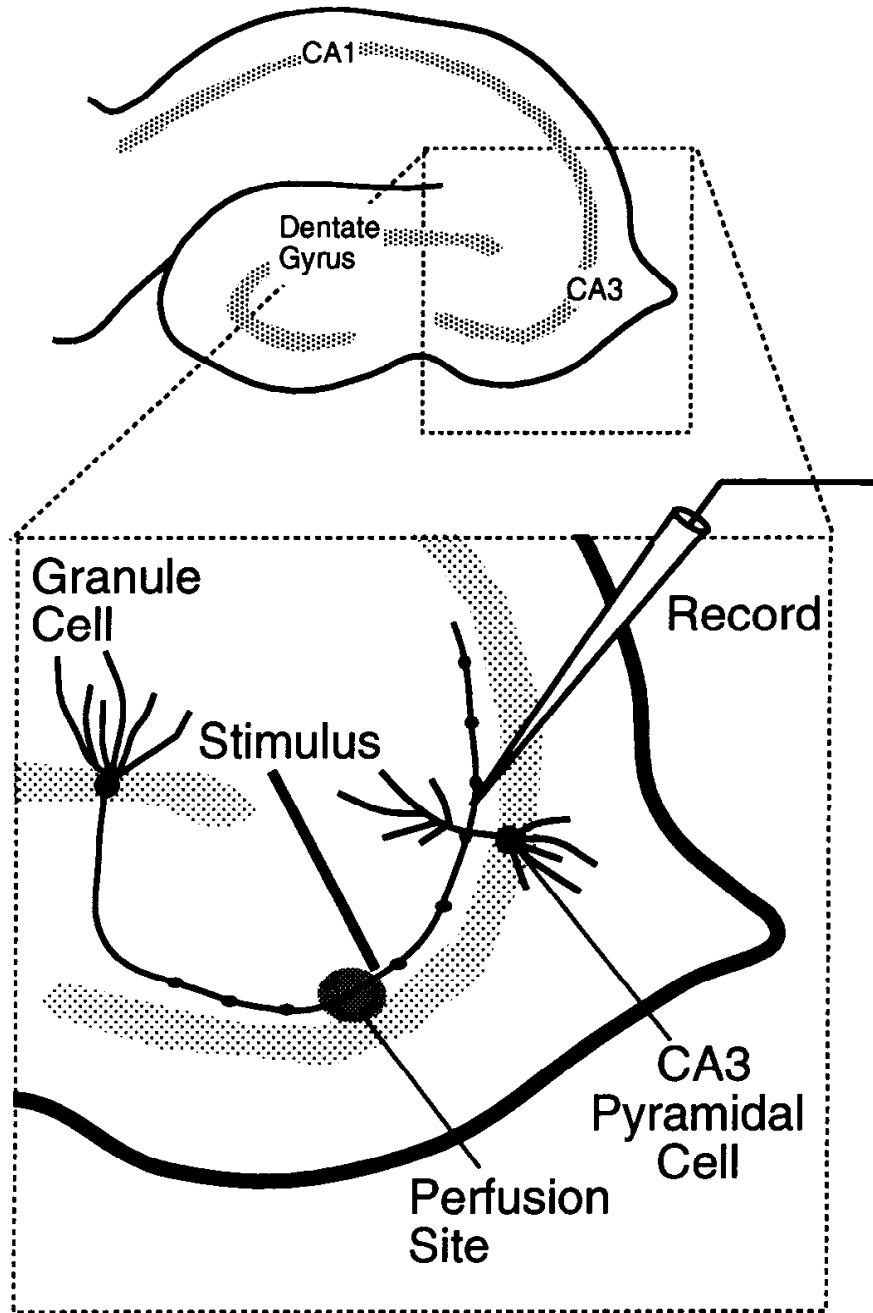

Figure 1. Schematic of a hippocampal slice. In the expanded diagram the connection between a granule cell and the proximal dendrites of a CA3 pyramidal cell, the mossy fiber synapse, is shown. The presynaptic terminals associated with these axons, indicated by periodic enlargements, are up to $5 \mu \mathrm{m}$ in diameter.

frequency-dependent facilitation. To measure calcium accumulations faithfully, we sampled rapidly (pairs of images at 10 $\mathrm{Hz}$ ) and carefully timed image acquisition relative to test pulses.

When the interval between action potentials is short compared to the decay time shown in Figure $2(1.1 \mathrm{sec})$ the calcium increase is directly proportional to the number of action potentials. As shown in Figure 3, this linear relationship between $\Delta\left[\mathrm{Ca}^{2+}\right]_{i}$ and the number of action potentials was found to hold when the number of action potentials at $100 \mathrm{~Hz}$ is 10 or fewer (in all of seven experiments). When more than 20 action potentials are delivered in rapid succession $\Delta\left[\mathrm{Ca}^{2+}\right]_{i}$ is smaller than expected (see Discussion).

When the stimulus interval is not short compared to the decay time of calcium, a qualitatively different temporal summation occurs. During low-frequency trains $\left[\mathrm{Ca}^{2+}\right]_{i}$ transients that accompany individual spikes are superimposed upon a gradually increasing $\left[\mathrm{Ca}^{2+}\right]$, that eventually plateaus, as shown in Figure $4 \mathrm{~A}$. For these stimulus conditions the interval between action potentials is sufficiently large to allow some, but not all, of the calcium from the previous action potential to be removed from
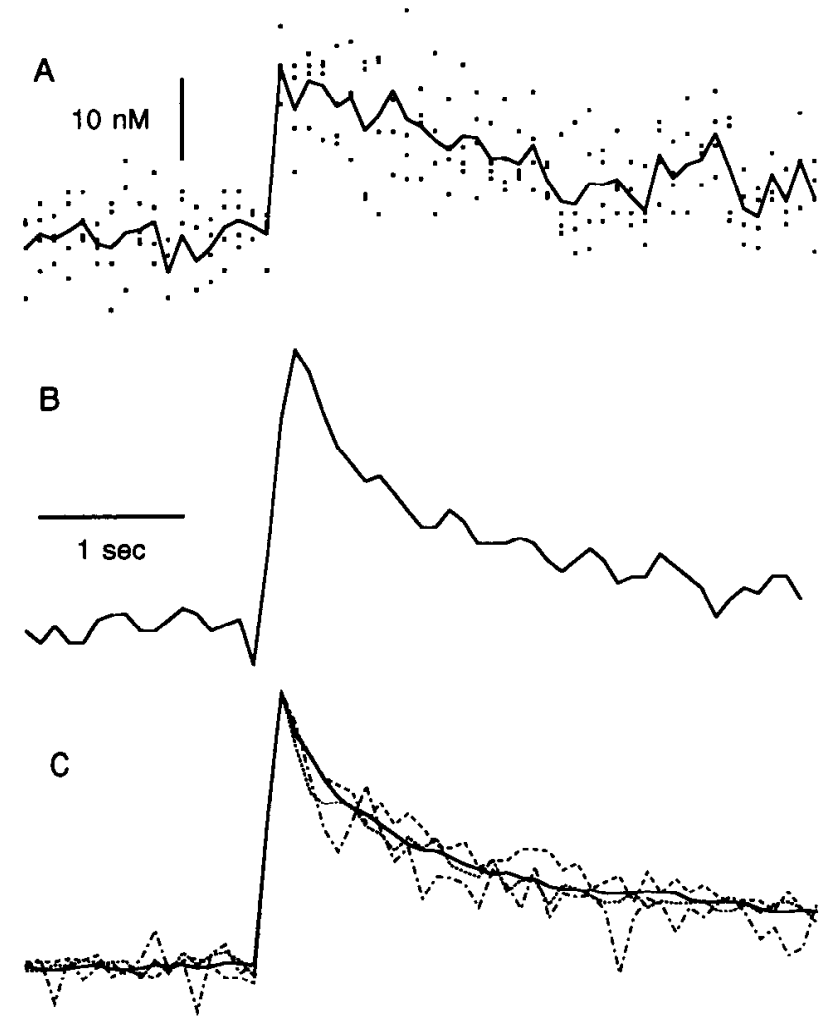

Figure 2. Stimulus-evoked calcium transients in mossy fiber presynaptic terminals. $A$, Calcium transient produced by a single action potential in an individual mossy fiber terminal. Four trials (dots) separated by more than $1 \mathrm{~min}$ were averaged to form the solid line. Calcium was determined from $340 \mathrm{~nm}: 380 \mathrm{~nm}$ ratio pairs acquired at $10 \mathrm{~Hz} . B$, Changes in the ratio of fura-2 fluorescence excited by $340 \mathrm{~nm}$ and 380 $\mathrm{nm}$ illumination produced in mossy fiber terminals by a single stimuli. $C$, The solid line represents the change in fura-2 fluorescence ratio in a large number of terminals, and the three dashed lines are calcium transients in individual terminals produced by 10 action potentials delivered at $100 \mathrm{~Hz}$. For the purpose of comparing the time courses, the traces were normalized to the peak calcium transient $\left(2.5 \mathrm{mM} \mathrm{Ca}^{2+}\right.$ and $T-$ $\left.32^{\circ} \mathrm{C}\right)(\operatorname{Exp} 71791 \mathrm{~A})$.

the cell before the arrival of the next action potential. This leads to a buildup of $\left[\mathrm{Ca}^{2}\right]$

We have compared the fura- 2 ratio changes rapidly measured during low-frequency trains with calcium accumulations predicted from linear superposition of transients produced by a single action potential. This approach begins with the observation that single action potentials increase $\left[\mathrm{Ca}^{2+}\right]_{i}$ abruptly by $\Delta\left[\mathrm{Ca}^{2+}\right]$, followed by an exponential decay to resting levels with a time constant, $\tau$. It is assumed that during a train of action potentials both $\tau$ and $\Delta\left[\mathrm{Ca}^{2+}\right]$ remain constant. For two action potentials separated by timc, $t$, the $\left[\mathrm{Ca}^{3+}\right]$ present immediately prior to the second action potential produced by the previous action potential is $\Delta\left[\mathrm{Ca}^{2+}\right] e^{-t / \tau}$. For a series of action potentials delivered at time $t_{0}, t_{1}, t_{2}, \ldots t_{n}$, the increases in the calcium level in the presynaptic terminal above resting levels just before action potentials 1 and $n$ are

$$
\Delta\left[\mathrm{Ca}^{2+}\right]_{1}=\Delta\left[\mathrm{Ca}^{2+}\right]_{0} e^{-\left(t_{1}-t_{0}\right) / \tau},
$$

and

$$
\Delta\left[\mathrm{Ca}^{2+}\right]_{n}=\Delta\left[\mathrm{Ca}^{2+}\right]_{n-1} e^{-\left(t_{n-t}-t_{n-1) /}\right.} .
$$

In the special case of a train with evenly spaced stimuli, the 

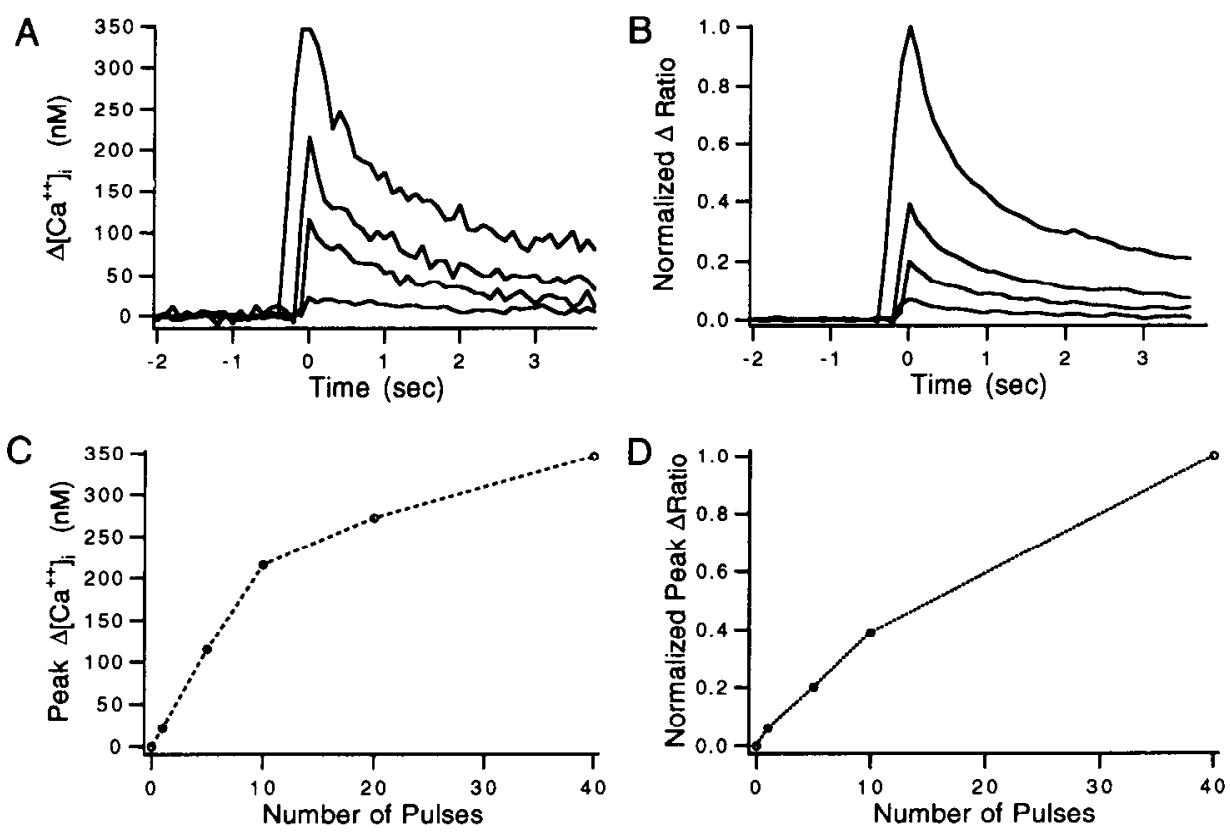

Figure 3. Calcium increases produced by $100 \mathrm{~Hz}$ trains containing different numbers of pulses. $A$, Presynaptic calcium increases produced by $1,5,10$, and 40 pulses. $B$, Normalized aggregate fura- 2 ratio changes produced by 1,5 , 10 , and 40 pulses. $C$, Peak $\Delta\left[\mathrm{Ca}^{2+}\right]$, for $A$. $D$. Peak aggregate fura -2 ratio changes for $B . \operatorname{In} B$ and $D$ traces are normalized relative to the peak ratio change produced by a $100 \mathrm{~Hz}$ train of 40 action potentials. Time $t=0$ corresponds to the end of the stimulus train (Exp71791B). The traces are single trials separated by more than $5 \mathrm{~min}$. calcium level present in the terminal before the $n$th stimulus is

$$
\Delta\left[\mathrm{Ca}^{2+}\right]_{n}=\Delta\left[C \mathrm{a}^{2+}\right]\left(\sum_{i=0}^{n} e^{-i t / \tau}-1\right) .
$$

Eventually, after a prolonged period of stimulation, the calcium plateaus and the increase in residual calcium level in the presynaptic terminal present at the lime just prior to a stimulation pulse $\left(\Delta\left[\mathrm{Ca}^{2+}\right]_{\text {platcau }}\right)$ is given by the limit of Equation 7 as $n$ $\rightarrow \infty$ :

$$
\Delta\left[\mathrm{Ca}^{2+}\right]_{\text {platcau }}=\Delta\left[\mathrm{Ca}^{2+}\right]\left(\frac{1}{1-e^{-1 / \tau}}-1\right),
$$

where $t$ is the interpulse interval (1/stimulus frequency). The linear superposition model predicts that the $\left[\mathrm{Ca}^{2+}\right]$, level present immediately preceding the action potentials in a train builds with a time constant $\tau$, independent of the stimulus frequency (see Eq. 7). A comparison of this predicted form and experiment is shown in Figure $4 C$, where the fura- 2 ratio values immediately before the next stimulus pulse are compared to a curve of the form $\Delta\left[\mathrm{Ca}^{2+}\right]\left(1-e^{-t / \tau}\right)$, with $\tau$ determined from Figure $4 B$. In the range of $0.5-2.5 \mathrm{~Hz}$, the match in time course is remarkably good. Clearly, though, for $5 \mathrm{~Hz}$ stimulation the experimentally observed time course does not agree with the predicted time course (see Discussion).

As shown in Figure $4 \mathrm{C},\left[\mathrm{Ca}^{2+}\right]_{\text {placau }}$ increases with elevated stimulus frequency. In Figure $4 D$ the experimentally determined relationship between $\left[\mathrm{Ca}^{2+}\right]_{\text {plateau }}$ and stimulus frequency is compared to the prediction of Equation 8 . There is excellent qualitative agreement between the shape of the curves, although the predicted values of the $\left[\mathrm{Ca}^{2+}\right]_{\text {placau }}$ are consistently larger than the observed values. This was found to hold true in all of seven experiments. Note that the predicted shape of the curve given by Equation 8 can be approximated by a linear function over the range of $0.5-2.5 \mathrm{~Hz}$, but that at frequencies below $(2 \tau)^{-1}$ very little calcium remains from previous stimuli when the next stimulus pulse is applied.

As shown in Figure 5, the number of impulses in the stimulus train and the temperature influenced $\Delta\left[\mathrm{Ca}^{2+}\right]_{i}$ decay kinetics. The larger the number of action potentials in a $40 \mathrm{~Hz}$ train, the
A
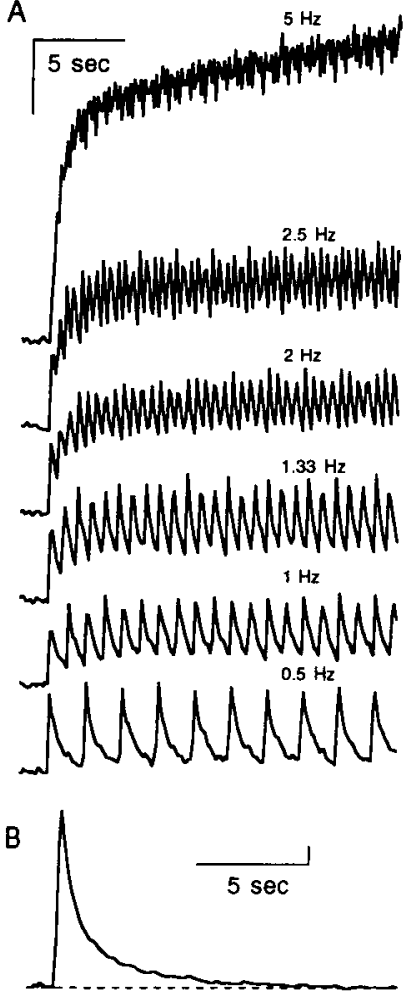

C
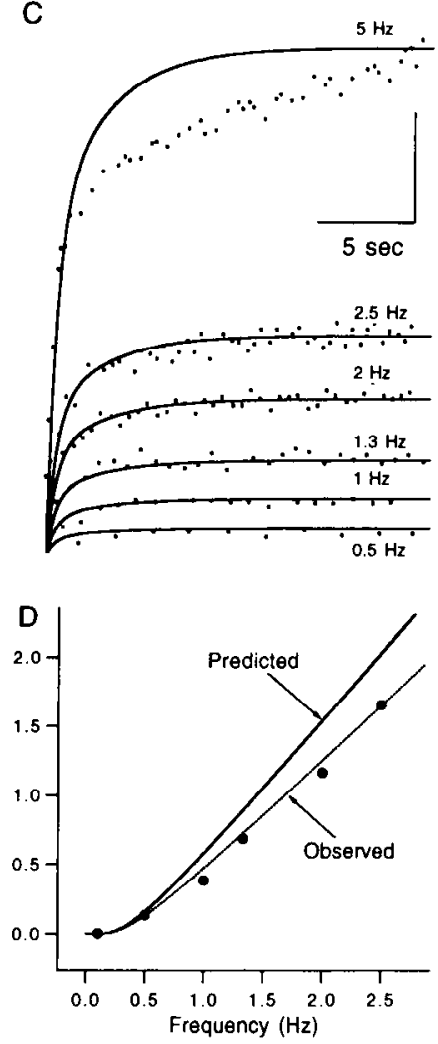

Figure 4. Fura-2 ratio changes produced by moderate frequency synaptic activation. $A$, Measurements of fura- 2 ratio changes produced by trains of action potentials delivered at the indicated stimulus frequency. Traces are vertically displaced for clarity. $B$. The ratio change produced by 10 action potentials delivered at $100 \mathrm{~Hz}$. $C$, Fura-2 ratio measurements corresponding to the traces shown in $A$ with the points corresponding to ratios measured just prior to stimulation. The solid traces are of the form $\left(1-e^{-t i r}\right)$, where $\tau$ was determined from $B . D$. Plateau values of the ratio change are plotted against the frequency of stimulation. The solid circles are the measured values determined in $C$. The solid line was determined from Equation 8 using the values of $\Delta\left[\mathrm{Ca}^{2+}\right]_{\text {, }}$ and $\tau$ from $B$. The dashed line is scaled by 0.85 to provide a good fit to the data. Vertical calibration corresponds to the change in aggregate fura-2 ratio produced by a single action potential (Exp72991). 
A
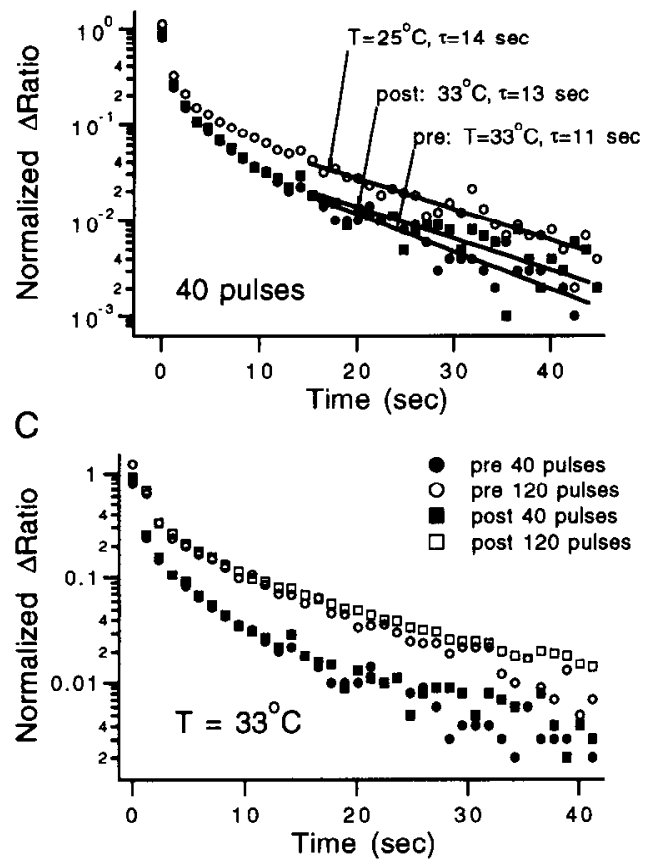

B

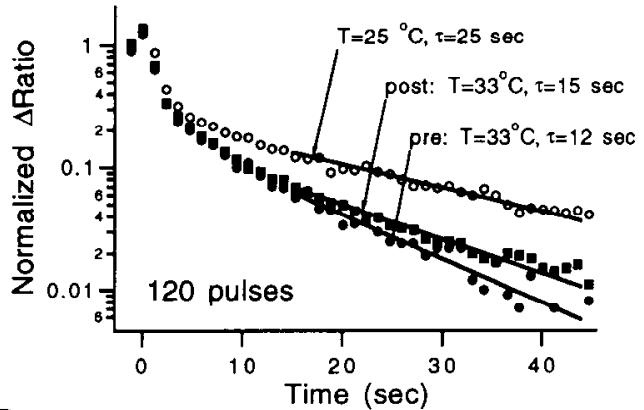

D
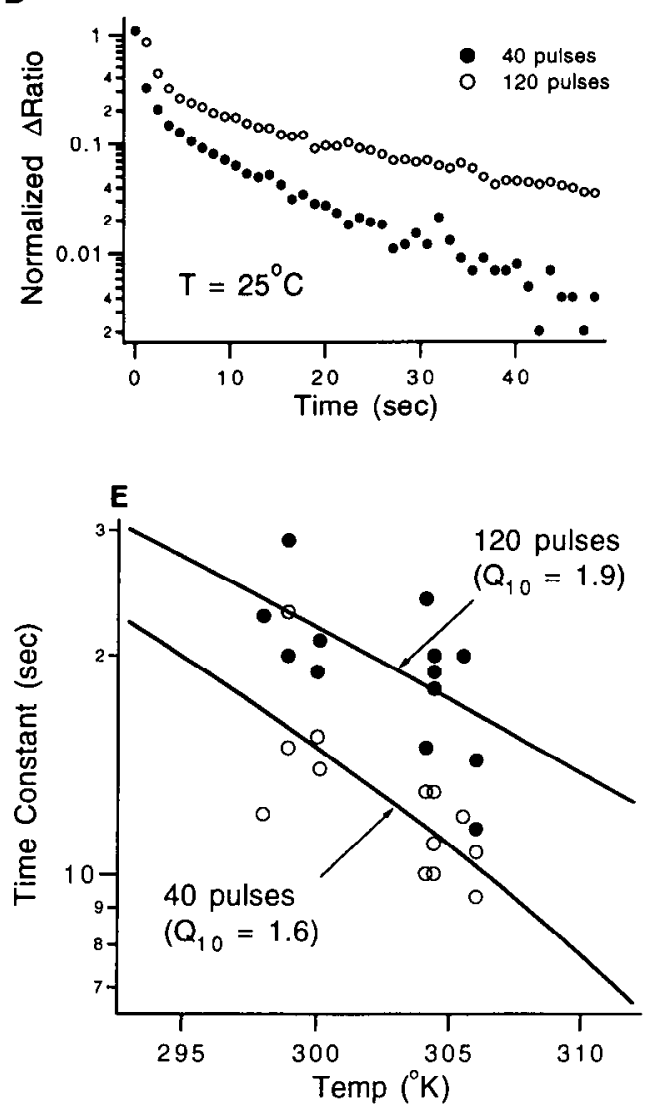

slower the time course of the calcium decay (Fig. $5 C, D, E$ ). Averaging a number of experiments similar to that of Figure 5, at $33^{\circ} \mathrm{C}$ the time constant of decay was $11 \pm 1.5 \mathrm{sec}( \pm \mathrm{SEM}, n=$ 7) for 40 pulses and $17 \pm 4 \sec ( \pm \mathrm{SEM}, n=7)$ for 120 pulses, while at $25^{\circ} \mathrm{C}$ the time constant of decay was $16 \pm 5 \mathrm{sec}( \pm \mathrm{SEM}$, $n=4)$ for 40 pulses and $23 \pm 4 \sec ( \pm \operatorname{SEM}, n=4)$ for 120 pulses. Similarly, as shown in Figure $5 E$, lowering the temperature prolonged the calcium transient corresponding to a $Q_{10}$ of 1.9 for a train of 40 pulses and $Q_{10}$ of 1.6 for 120 pulses.

The role of presynaptic calcium in short-term synaptic enhancement at mossy fiber synapses produced by high-frequency stimulation

To elucidate the role of $\Delta\left[\mathrm{Ca}^{2+}\right]_{i}$ in PTP, we simultaneously measured $\Delta\left[\mathrm{Ca}^{2+}\right]_{i}$ in individual presynaptic terminals and the field EPSP following tetanic stimulation. The results from a typical experiment are shown in Figure 6 . Following a $50 \mathrm{~Hz}$ train consisting of 100 pulses, synaptic transmission was en- hanced and $\left[\mathrm{Ca}^{2}\right]_{i}$ was elevated (Fig. $6 A$ ). The enhancement and $\Delta\left[\mathrm{Ca}^{2+}\right]_{i}$ decayed following termination of the train. For the lower values of $\Delta\left[\mathrm{Ca}^{2+}\right]_{i}$ observed near the end of the decay there is an approximately linear relationship between the change in normalized PSP slope and $\Delta\left[\mathrm{Ca}^{2+}\right]_{i}$. In this particular case, an increase of about $16 \mathrm{nM}$ corresponded to a twofold enhancement (when $\Delta$ (normalized PSP slope) $=1$ ), similar to our previous results (Regehr and Tank, 199la) where $17 \pm 4$ nм corresponded to a twofold enhancement. For about 10-20 sec immediately following tetanic stimulation there was a deviation from a linear approximation relating the synaptic enhancement to $\Delta\left[\mathrm{Ca}^{2+}\right]_{i}$ (Fig. $6 B$ ). Also note that calcium decayed more rapidly than did enhancement. Similar results were observed when aggregate fura-2 ratio changes, instead of presynaptic calcium levels from individual terminals, were compared to EPSP following high-frequency stimulation (data not shown).

The mismatch between the time course of calcium decay and the decay of synaptic enhancement suggested that for mossy 

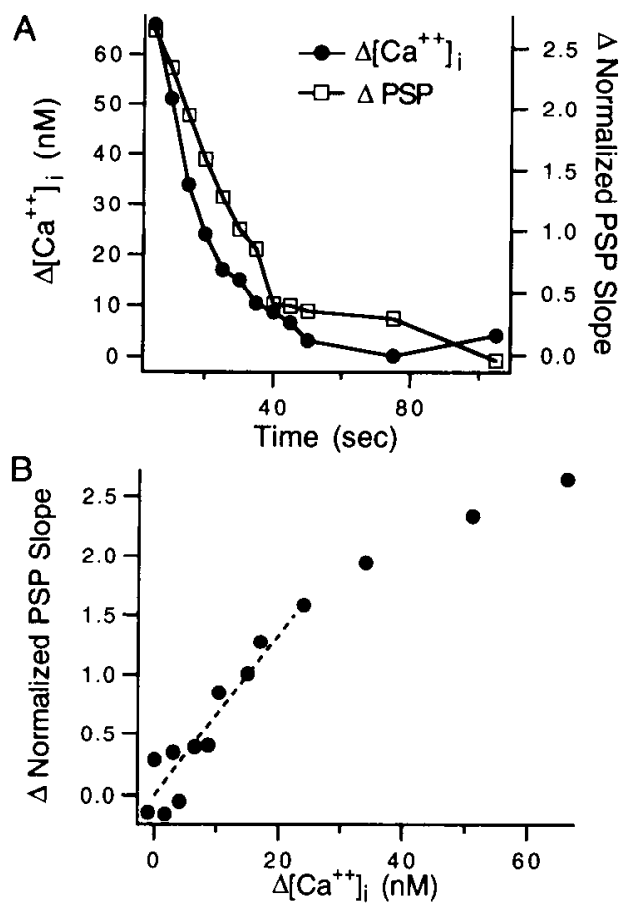

Figure 6. Decay of PSP enhancement and $\Delta\left[\mathrm{Ca}^{2+}\right]$, in an individual terminal following stimulation for $2 \mathrm{sec}$ at $50 \mathrm{~Hz}$ in $2.5 \mathrm{mM} \mathrm{Ca}^{2+}, T=$ $32^{\circ} \mathrm{C}$. $A$, Change in normalized PSP slope and $\Delta\left[\mathrm{Ca}^{2+}\right]$, in an individual presynaptic terminal following tetanic stimulation. $\triangle$ Normalized PSP slope corresponds to (PSP slope)/(unfacilitated PSP slope) - $1 . B$, Change in normalized PSP slope as a function of $\Delta\left[\mathrm{Ca}^{2+}\right]$, for the data shown in $A$. The dashed line was drawn by eye and corresponds to a twofold enhancement for a $16 \mathrm{~nm}$ increase in presynaptic calcium (Exp122290A).

fiber terminals the duration of PTP is not determined solely by $\Delta\left[\mathrm{Ca}^{2+}\right]$. If, as at the crayfish neuromuscular junction, calcium dynamics dictate the duration of enhancement, then manipulations that alter the $\Delta\left[\mathrm{Ca}^{2+}\right]$, time course should produce a concomitant change in the duration of enhancement. As shown in Figure 5, calcium dynamics are influenced by the number of action potentials in a train and by the temperature. These two manipulations have also been reported to influence the time course of PTP at other synapses (McNaughton, 1982). We therefore performed experiments to examine quantitatively the influence of temperature and the number of pulses in a stimulus train on the kinetics of enhancement and $\left[\mathrm{Ca}^{2+}\right]_{\text {. }}$.

Lowering the temperature from $33^{\circ} \mathrm{C}$ to $25^{\circ} \mathrm{C}$ had a number of ancillary effects: it decreased the conduction velocity as reflected by an increase in the time to peak of the presynaptic volley; it increased the amplitude of the unfacilitated PSP slope; it decreased the amount of enhancement, as shown in Figure 7, $A a$ and $B a$; and transient depression of release following a train became pronounced, as indicated by the gradual buildup of PSP slope for several pulses following the cessation of tetanic stimulation (compare Fig. 7, $A b$ to $B b$ ). More relevant to the matter at hand, lower temperatures slowed the time constant of decay for synaptic enhancement and for the $\Delta\left[\mathrm{Ca}^{2+}\right]_{i}$ (compare Fig. 7, $A c$ to $B c$ ). The duration of synaptic enhancement was, however, affected to a greater extent than was $\Delta\left[\mathrm{Ca}^{2+}\right]_{i}$. For example, for the experiment displayed in Figure 7, a decrease in the temperature increased the decay time constant of synaptic enhancement from $25 \mathrm{sec}$ to $170 \mathrm{sec}$, while increasing the time course of the decay of calcium from $14 \mathrm{sec}$ to $23 \mathrm{sec}$. This differential

\begin{tabular}{|c|c|c|c|}
\hline $\operatorname{Temp}\left({ }^{\circ} \mathrm{C}\right)$ & $\begin{array}{l}\text { Number of } \\
\text { pulses }\end{array}$ & $\begin{array}{l}\text { Time constant of } \\
{\left[\mathrm{Ca}^{2+}\right] \text {, decay }(\mathrm{sec})}\end{array}$ & $\begin{array}{l}\text { Time constant of } \\
\text { PSP decay (sec) }\end{array}$ \\
\hline $31-33$ & 40 & $11 \pm 1(n=5)$ & $18 \pm 3 \quad(n=5)$ \\
\hline $31-33$ & 120 & $17 \pm 2(n=5)$ & $23 \pm 2 \quad(n=5)$ \\
\hline $25-27$ & 40 & $17 \pm 4(n=3)$ & $37 \pm 15(n=3)$ \\
\hline $25-27$ & 120 & $24 \pm 3(n=3)$ & $90 \pm 40(n=3)$ \\
\hline
\end{tabular}

In the experiments summarized here, time course of decay of field PSP slope and aggregate fura-2 ratio were measured simultaneously. For calcium decay and PSP decay at $31-33^{\circ} \mathrm{C}$, time constants were determined by a fit to the function $a \cdot e$ "r for the $\Delta$ ratio or $\triangle P S P$ slope over the time period 10-40 sec following the termination of tetanic stimulation. For the decay of PSP at $25-27^{\circ} \mathrm{C}$, fits were made over a range of about 40-100 sec to avoid the prominent depression that immediately followed tetanic stimulation.

effect of temperature was reliably observed (although the data in Fig. 5 are an example of a particularly large effect). Thus, lowering the temperature accentuated the temporal mismatch in the decay kinetics of $\Delta\left[\mathrm{Ca}^{2}\right]_{i}$ and synaptic enhancement.

Table 1 summarizes a number of experiments in which fura-2 ratio and enhancement were measured simultaneously. Increasing the number of pulses in a stimulus train extended the time course of decay for both synaptic enhancement and fura- 2 ratio. At $31-33^{\circ} \mathrm{C}$, incrcasing the number of pulses in a $40 \mathrm{~Hz}$ train from 40 to 120 produced small changes of comparable amplitudes in the decay time constant. At $25-27^{\circ} \mathrm{C}$, increasing the number of pulses in a $40 \mathrm{~Hz}$ train from 40 to 120 had a greater effect on the decay time constant of enhancement than on the decay time constant of calcium. In 15 of 16 experiments summarized in Table 1, calcium decayed more rapidly than did synaptic enhancement and, according to the Wilcoxon pairedsample test, a nonparametric analog of the paired sample $t$ test (Zar, 1974), the decay of calcium was significantly more rapid than the decay of PSP slope for the data summarized in Table $1(p=0.001)$.

Thus, manipulations that prolong the decay of enhancement are accompanied by a corresponding change in the time course of calcium decay. In addition, the temporal mismatch between the $\Delta\left[\mathrm{Ca}^{2+}\right]_{i}$ decay and the decay of enhancement is accentuated at lower temperatures.

\section{Synaptic enhancement during low-frequency trains}

As shown in Figure 8, synaptic transmission is enhanced during low-frequency trains $(0.1-5 \mathrm{~Hz})$. Synaptic enhancement builds rather slowly and eventually plateaus. The time course of the buildup of synaptic enhancement for various frequencies is shown in Figure $8 A$. As shown in Figure $8 B$, as the stimulus frequency is increased, the plateau value also increases. The buildup of synaptic enhancement was well fit by a single exponential with a time constant that depended on the stimulus frequency (Fig. $8 C$ ). The time constant is plotted against stimulus frequency in this manner to facilitate comparison with a kinetic model we present below.

During trains delivered at greater than $5 \mathrm{~Hz}$ the presynaptic volley broadened, the latency was increased, and the PSP slope peaked relatively early in the train and then declined (data not shown). Such an effect was also sometimes observed, to a smaller extent, for $5 \mathrm{~Hz}$ stimulation.

We tested the possibility of spike broadening contributing to 
A a

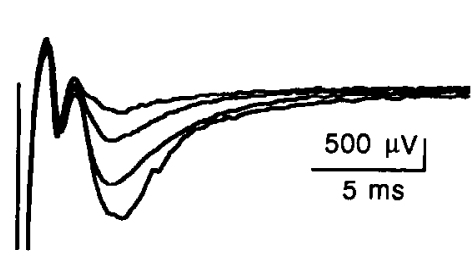

B a

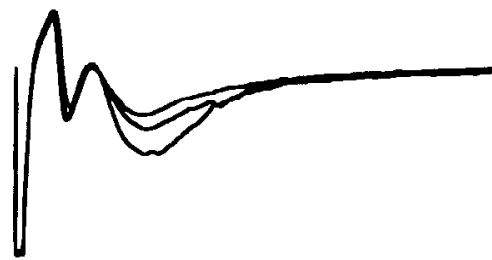

Figure 7. The effect of temperature and number of stimulus pulses on the time course of synaptic enhancement produced by tetanic stimulation. $A, T=$ $33^{\circ} \mathrm{C}$. $a$, Representative extracellular PSPs recorded following tetanic stimulation (in order of decreasing size following a $3 \mathrm{sec} 40 \mathrm{~Hz}$ stimulus train at times, in seconds: $9,21,39,75) . b$, Normalized PSP slope following stimulation by 120 pulses (two trials) and 40 pulses (two trials). $c$, Semilog plot of the same data as shown in $b$ with the individual trials represented by different symbols. The two thick solid lines are exponential fits over the range of 15$45 \mathrm{sec}$ to the average of the two trials for stimulation with 40 pulses and 120 pulses. $B, T=25^{\circ} \mathrm{C}$. $a$, Representative extracellular PSPs recorded following tetanic stimulation (in order of decreasing size following a $3 \mathrm{sec} 40 \mathrm{~Hz}$ stimulus train at times, in seconds: $27,54,129$ ). $b$, Normalized PSP slope following stimulation by 120 pulses. $c$, Semilog plot of the same data as shown in $b$ with the individual trials represented by markers, the average of two trials by a solid line. The thick solid line is an exponential fit over the range of $40-100$ sec. $\triangle$ Normalized PSP slope corresponds to (PSP slope)/(unfacilitated PSP slope) -1 . Test pulses were delivered once every $3 \mathrm{sec}$ and extracellular calcium was $2 \mathrm{~mm}$ for this experiment (Exp062591B).
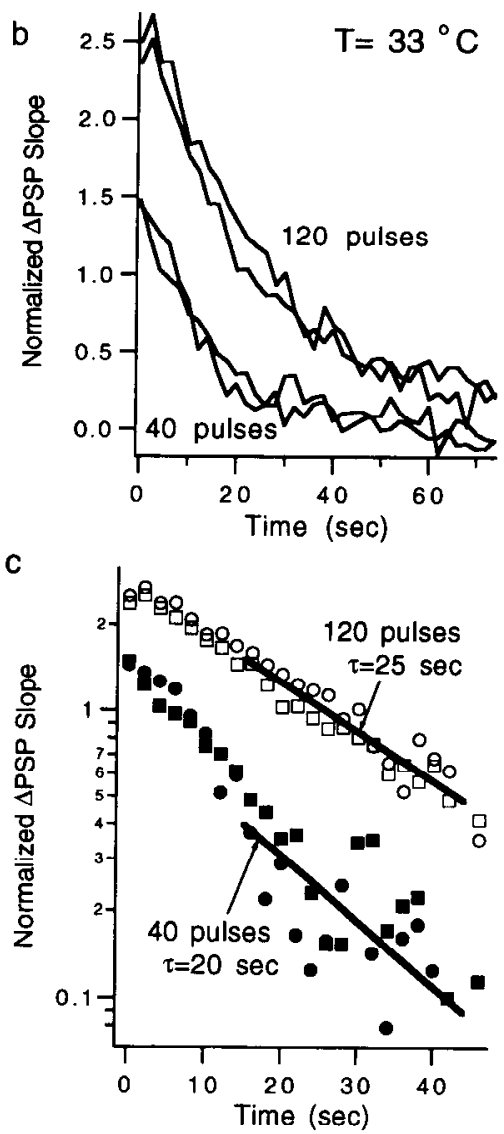

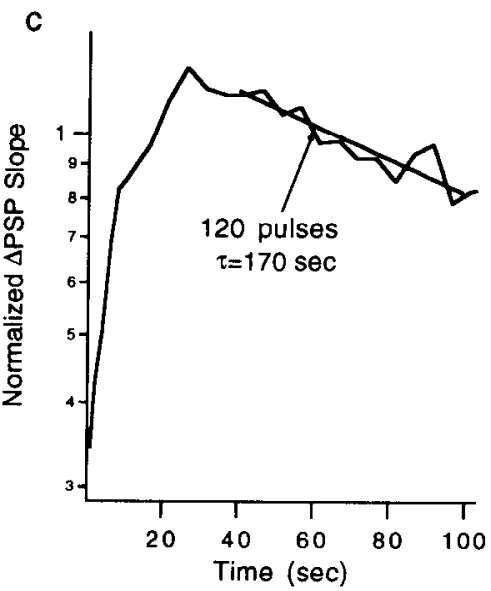

the observed synaptic enhancement. Synaptic transmission has been shown to be sensitive to spike width at a variety of synapses, including the squid giant synapse, where a $30 \%$ increase in the spike width can produce a $190 \%$ enhancement of synaptic transmission (Augustine, 1990). Although the presynaptic volley does not remain constant during stimulus trains of greater than $5 \mathrm{~Hz}$, within our measurement accuracy there was no detectable change in spike width for frequencies of less than $5 \mathrm{~Hz}$ (data not shown). We therefore estimate that the spike broadening under our experimental conditions is less than $10 \%$. This suggests that spike broadening could not account for the observed synaptic enhancement unless the sensitivity to spike width was much greater at this synapse than the sensitivity described elsewhere.

During low-frequency trains, after synaptic enhancement has plateaued, the relationship between $\Delta\left[\mathrm{Ca}^{2+}\right]_{i}$ and enhancement is well approximated by a linear function, as shown in Figure 9. For 13 experiments it was found that a twofold enhancement corresponded to an increase of $21 \pm 3 \mathrm{~nm}$ calcium.

As shown in Figure 4, low-frequency trains produced a buildup of calcium in presynaptic terminals. We compared the buildup of calcium to the buildup of synaptic enhancement by simultaneously measuring the fura- 2 fluorescence ratio and the field PSP. At the onset of low-frequency trains there is a clear mismatch in the time course of $\Delta\left[\mathrm{Ca}^{2+}\right]_{i}$ and the buildup of synaptic enhancement. $\Delta\left[\mathrm{Ca}^{3+}\right]_{i}$ platcaued with a time constant of 1-1.5 sec, which was similar to the decay time constant for calcium produced by a single action potential. In contrast, PSP enhancement built up with a time constant of 4-12 sec, as shown in Figure 10. This mismatch between the buildup of calcium and enhancement at the onset of a stimulus train was observed in all of 15 experiments.

\section{Calcium transients and synaptic enhancement in the presence of exogenous calcium buffer}

The observations described thus far have not established a causal relationship between increases in $\left[\mathrm{Ca}^{2+}\right]_{i}$ and synaptic enhancement. Indeed, the observation that during and following stimulus trains a mismatch in the time course of calcium transients and the time course of PSP enhancement suggests that the role of $\Delta\left[\mathrm{Ca}^{2+}\right]_{i}$ in short-term plasticity at this synapse is, at the very least, less straightforward than at the crayfish neuromuscular junction.

A crucial prediction of the hypothesis that $\Delta\left[\mathrm{Ca}^{2+}\right]$, causes short-term enhancement at the mossy fiber synapse is that if 
A
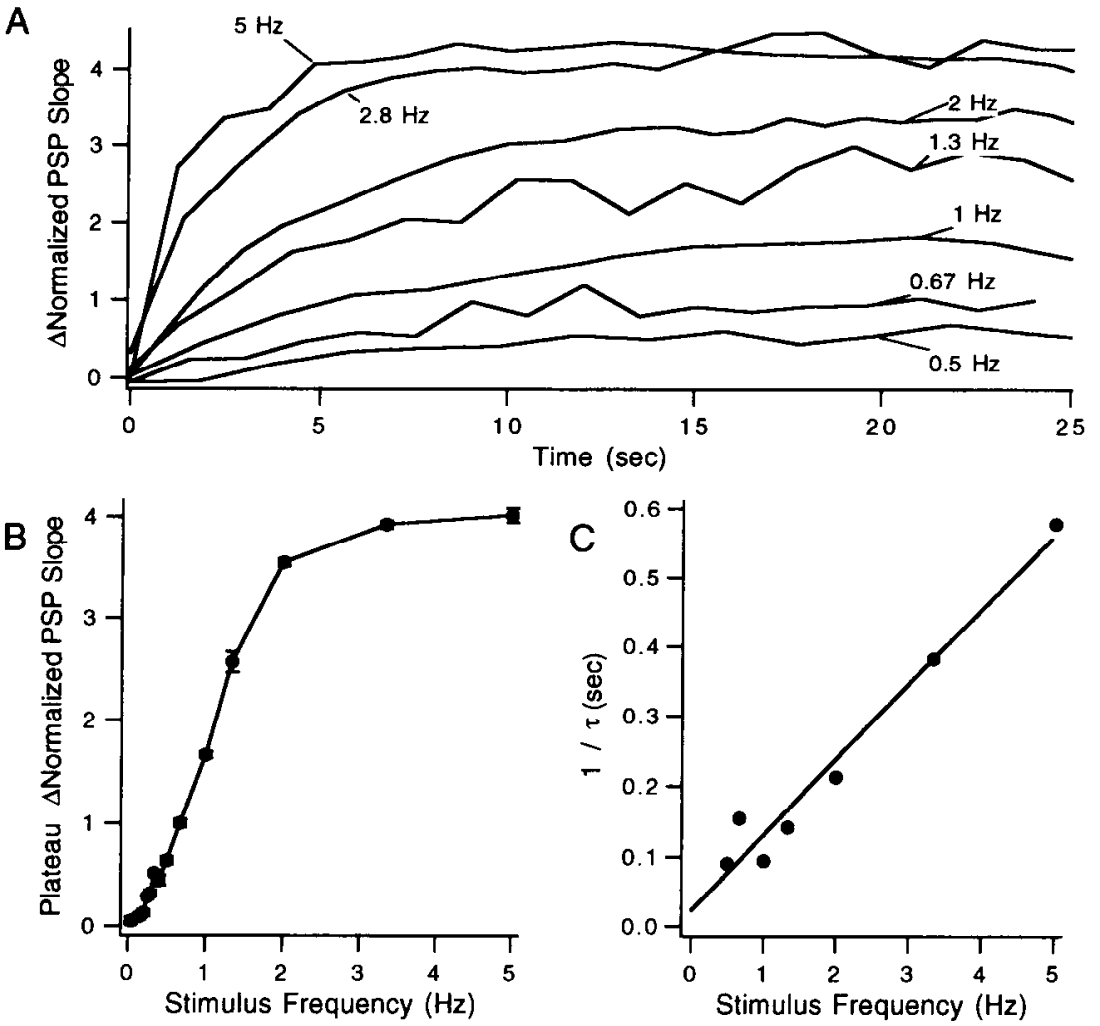

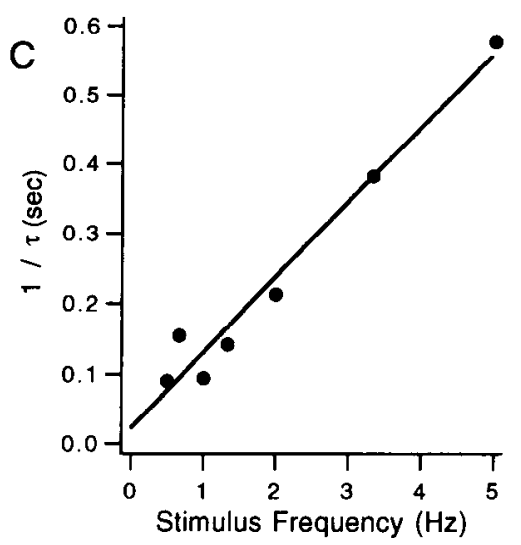

Figure 8. Enhancement of field potential during low-frequency stimulation. $A$, The change in normalized field potential slope as a function of time for trains delivered at the indicated stimulus frequencies. $B$, The change in plateau PSP slope as a function of frequency. PSP slopes are the average after the response had plateaued (i.e., at least $20 \mathrm{sec}$ after the onset of stimulation) and the error bars are standard deviations. $C$, The inverse of the time constant of PSP enhancement is plotted as a function of the stimulus frequency. The time constant $\tau$ was determined from a fit to the function $a\left(1-e^{-1 / r}\right)$. $\triangle$ Normalized PSP slope corresponds to (PSP slope)/(unfacilitated PSP slope)- 1 $(\operatorname{Exp} 92191 B)$.
$\Delta\left[\mathrm{Ca}^{2+}\right]$ kinetics are slowed, the kinetics of PSP enhancement should also be slowed. If calcium dynamics are made sufficiently slow, then the time course of enhancement and calcium should be well matched. We, thus, decided to manipulate the $\Delta\left[\mathrm{Ca}^{2+}\right]_{i}$ dynamics by adding exogenous calcium buffer to the presynaptic terminals.

Based upon experiments at the crayfish neuromuscular junction and theoretical considerations, the time course of $\Delta\left[\mathrm{Ca}^{2+}\right]_{i}$ decay is well approximated by an exponential decay with a time constant proportional to the buffer capacity of the presynaptic terminal (Tank et al., 1991; Neher and Augustine, 1992). When the buffer capacity of the presynaptic terminal is increased, it takes more time to load up the buffer with calcium and to remove the calcium from the presynaptic terminal. To produce a sufficiently large change in the calcium decay time, it was necessary to fill the presynaptic terminals with large quantities of exogenous buffer. Using EGTA-AM to increase the calcium buffer capacity in presynaptic terminals profoundly slowed the time course of calcium buildup and decay. One example is shown in Figure 11, where the buildup in response to $5 \mathrm{~Hz}$ and $2 \mathrm{~Hz}$ stimulus trains is well approximated by a single exponential with a time constant of $25 \mathrm{sec}$. In seven experiments EGTA reliably slowed the time constant of both the buildup and the decay of calcium, although there was some quantitative variation in the magnitude of this effect. As also shown in Figure 11, the slowing of calcium buildup and decay was accompanied by a slowing of the rate of buildup and decay of the synaptic enhancement. The enhancement was slowed to a greater extent, such that both synaptic enhancement and calcium now followed the same time course.

The fact that when calcium kinetics are appreciably slowed the time course of synaptic enhancement then tracks the calcium changes without a delay provides strong evidence that increases in $\left[\mathrm{Ca}^{2+}\right]_{i}$ cause short-term enhancement at the mossy fiber synapse. But why is there a delay between calcium changes and enhancement for normal buffer conditions?

\section{A calcium binding site with slow kinetics can account for the temporal mismatch between residual calcium and enhancement}

We suggest a simple model to account for the fact that the synaptic enhancement appears to be causally related to the calcium buildup but occurs with a time delay under normal calcium

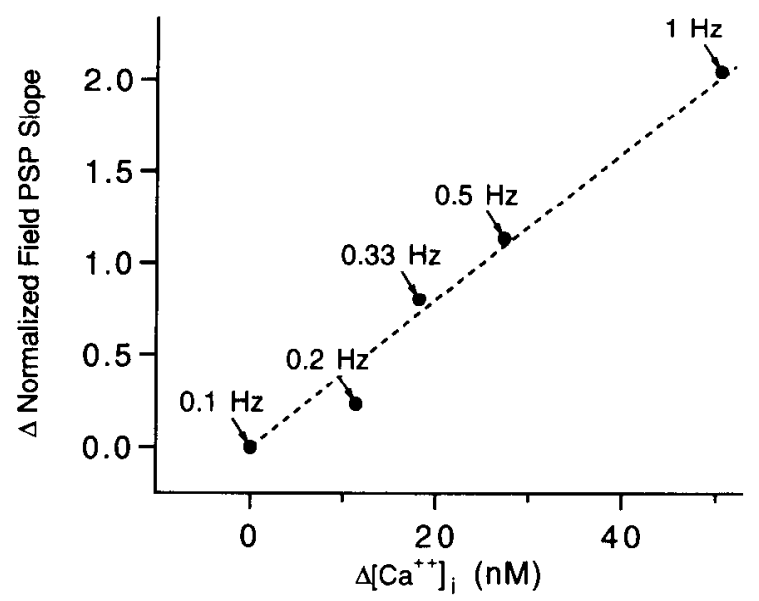

Figure 9. Relationship between enhancement and $\Delta\left[\mathrm{Ca}^{2+}\right]$, during lowfrequency trains, after $\Delta\left[\mathrm{Ca}^{2+}\right]$, and enhancement have plateaued (i.e., at least $20 \mathrm{sec}$ after the onset of stimulation). The dashed line corresponds to a twofold enhancement for each $25 \mathrm{nM}$ increase in $\left[\mathrm{Ca}^{2+}\right]$. $\triangle$ Normalized PSP slope corresponds to (PSP slope)/(unfacilitated PSP slope)-1 (Expl 22090B). 
A

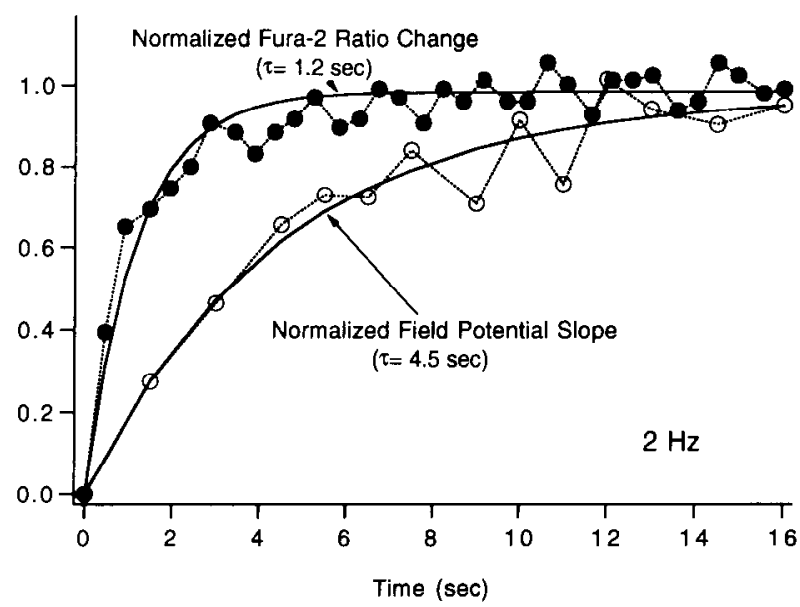

B

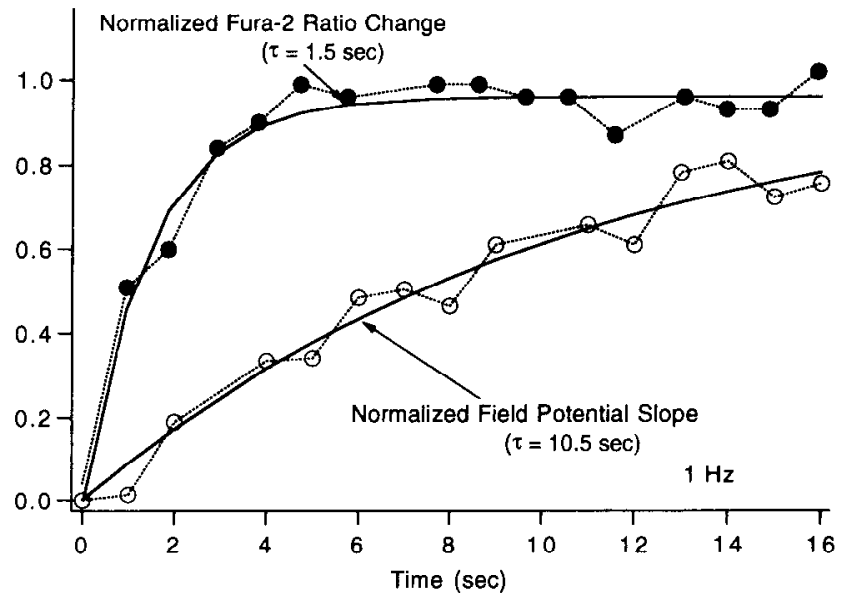

Figure 10. At the onset of low-frequency trains residual calcium builds up more rapidly than does synaptic enhancement. Normalized aggregate fura- 2 ratio changes and field potential slopes are plotted as a function of time for $2 \mathrm{~Hz}(A)$ and $1 \mathrm{~Hz}(B)$ stimulation. To enable comparison of the time course of calcium increases and the buildup of enhancement, the ratio change and field potential slopes have been normalized such that 0 corresponds to the value at the commencement of stimulation and 1 corresponds to the plateau value observed after $25 \mathrm{sec}$ of stimulation. Note that the normalized fura- 2 ratio change is plotted for the time period immediately preceding the stimulus pulse in a manner similar to Figure $4 C$. The time constant $\tau$ was determined from a fit to the function $\left(1-e^{t / *}\right)$ for the indicated data $(\operatorname{Exp} 72991)$.

buffering conditions. The model assumes that short-term synaptic enhancement is produced by a Ca-dependent first-order reaction product, and that the slow kinetics of the $\mathrm{Ca}$-dependent reaction produce the experimentally observed temporal mismatch. Wc assume that calcium binds to a substrate $(\mathrm{X})$ to produce a product, $\mathrm{CaX}^{*}$, that increases the probability of release:

$$
\begin{array}{r}
p \propto\left[\mathrm{CaX}^{*}\right], \\
\mathrm{Ca}^{2+}+X \underset{k^{-}}{\stackrel{k^{+}}{\longrightarrow}} \mathrm{CaX} X^{*},
\end{array}
$$

where $k^{+}$is the forward rate constant $\left(\sec ^{-1} \mathbf{M}^{-1}\right), k^{-}$is the reverse rate constant $\left(\mathrm{sec}^{-1}\right), K_{B}=k^{-} / k^{+}$is the dissociation constant (M), $p$ is the probability of release, $[X]$ is the concentration of unbound substrate $(\mathrm{M}),\left[\mathrm{Ca}{ }^{*}\right]$ is the concentration of activated substrate (M), $\left[X_{t}\right]=[X]+\left[\mathrm{CaX}^{*}\right]$ is total concentration of substrate $(\mathrm{M})$, and $\left[\mathrm{Ca}^{2+}\right]$ is calcium concentration (M).

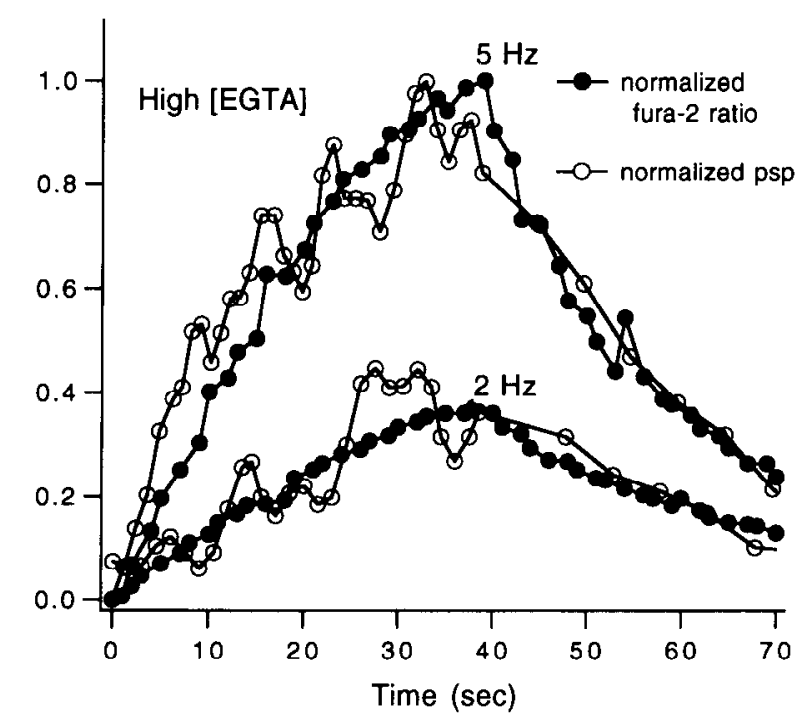

Figure 1I. For conditions of increased calcium bufters in presynaptic terminals there is a roughly linear relationship between enhancement and $\left[\mathrm{Ca}^{2+}\right]$, in presynaptic terminals. After loading the slice with EGTA$\mathrm{AM}$, the time course of buildup and decay of aggregate fura- 2 ratio (solid circles) and PSP enhancement (open circles) are similar to each other and slowed for both $5 \mathrm{~Hz}$ and $2 \mathrm{~Hz}$ stimulation. To enable comparison of the time course of calcium increases and the buildup of enhancement, the ratio change and field potential slopes have been normalized such that 0 corresponds to the value at the commenecment of stimulation and 1 corresponds to the peak value for $5 \mathrm{~Hz}$ stimulation (Exp92191 A). Hz stimulation (Exp92191A).

The time evolution of this reaction is described by the differential equations

$$
\begin{aligned}
& \frac{d\left[\mathrm{CaX}^{*}\right]}{d t}=k^{+}\left[\mathrm{Ca}^{2+}\right][\mathrm{X}]-k^{-}\left[\mathrm{CaX}^{*}\right], \\
& \frac{d\left[\mathrm{CaX} X^{*}\right]}{d t}=k^{+}\left[\mathrm{Ca}^{2+}\right]\left(\left[\mathrm{X}_{t}\right]-\left[\mathrm{CaX} X^{*}\right]\right)-k^{-}\left[\mathrm{CaX}^{*}\right], \\
& \frac{d\left[\mathrm{CaX} X^{*}\right]}{d t}=k^{+}\left[\mathrm{Ca}^{2+}\right]\left[X_{t}\right]-\left[\mathrm{CaX}^{*}\right]\left(k^{+}\left[\mathrm{Ca}^{2+}\right]+k^{-}\right) .
\end{aligned}
$$

For the case in which there is a calcium step from 0 to $\left[\mathrm{Ca}^{2+}\right]_{1}$ at time $t=0$ seconds, there is an analytical solution.

$$
\begin{aligned}
{\left[\mathrm{CaX}^{*}\right] } & =\left[\mathrm{CaX}^{*}\right]_{\text {placcau }}\left(1-\mathrm{e}^{-\ell / \tau}\right), \\
{\left[\mathrm{CaX}^{*}\right]_{\text {rlateaul }} } & =\frac{\left[\mathrm{Ca}^{2+}\right]_{1}\left[\mathrm{X}_{t}\right]}{K_{B}} \frac{1}{\left(1+\frac{\left[\mathrm{Ca}^{2+}\right]_{1}}{K_{B}}\right)}, \\
\frac{1}{\tau} & =k^{+}\left[\mathrm{Ca}^{2+}\right]_{1}+k^{-},
\end{aligned}
$$

where $\left[\mathrm{CaX}^{*}\right]_{\text {plateau }}$ is the steady-state value attained after a prolonged calcium step.

Thus, the model predicts that a step increase in calcium concentration activates a substrate with a time course, characterized by the time constant in Equation 14, that depends upon the magnitude of the calcium step and the on and off rates of the binding site. For comparison with experiment, we provide an example in Figure $12 B$ of the numerically computed buildup of the activated substrate produced by the calcium steps shown in (Fig. 12A). We also demonstrate that when the numerically 
A

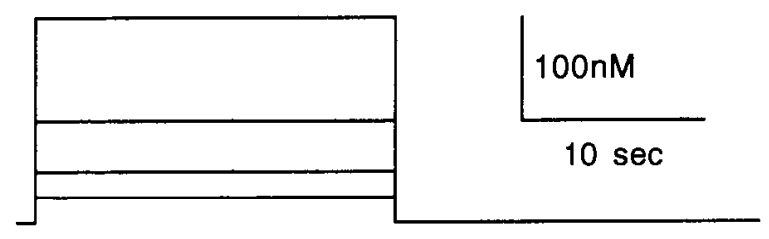

B
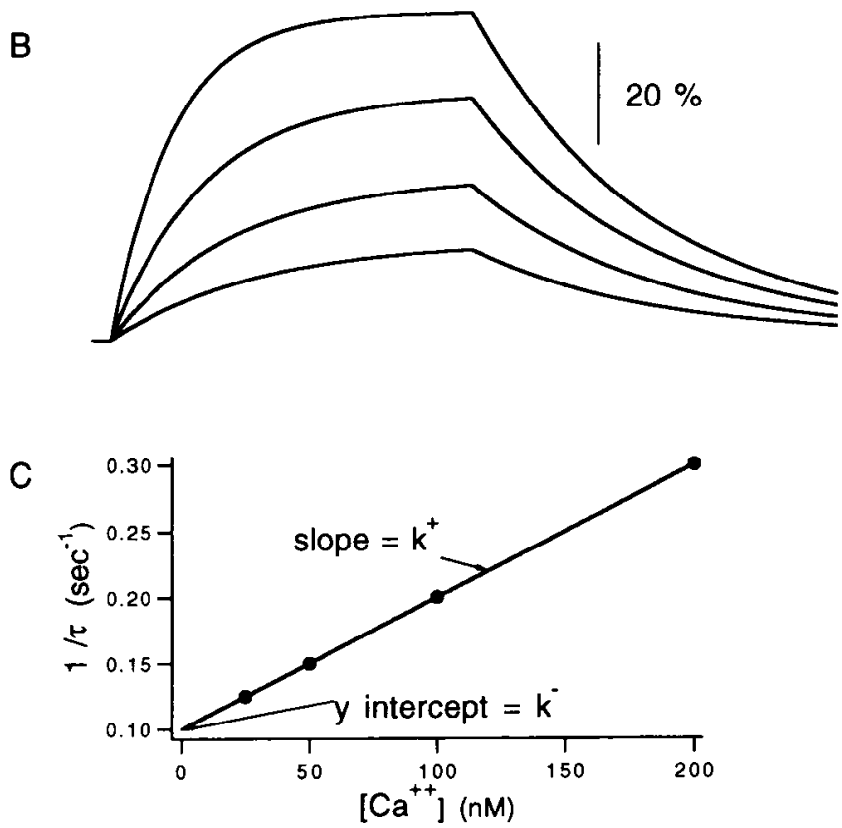

Figure 12. Simulations showing the activation of a calcium binding substrate by imposed calcium steps similar to those observed during low-frequency trains. The percentage of activation was determined using Equation $11 ; k^{\prime}=10^{6} \mathbf{M}^{-1} \mathrm{sec}{ }^{\prime} ; k=0.1 \mathrm{sec}^{\prime}$. $A$, Residual calcium steps. $B$, Activation of substrate. $C$, The inverse of the time constant of buildup plotted against the amplitude of the calcium step.

computed data is plotted as $\tau^{-1}$ versus the magnitude of the calcium step, a straight line is produced that has a slope of $k^{+}$ and a y-intercept of $k^{-}$.

The calcium level dependence of the time constant of buildup of the activated substrate in this model (Fig. $12 \mathrm{C}$ ) is reminiscent of the dependence of the time constant of the huildup of synaptic enhancement observed during low-frequency trains delivered to mossy fiber terminals (Fig. 8C). Higher-frequency trains that produce larger calcium steps have a more rapid rise in synaptic enhancement. Under normal calcium buffering conditions the time constant of the calcium buildup is short compared to that of the synaptic enhancement. Thus, for comparison with the model, the accumulation of calcium during the stimulus trains can be crudely approximated by a step from resting calcium levels, and the kinetic properties of the putative binding site can be estimated from our experimental measurements of calcium and enhancement. We estimate that $k^{-}$is about $0.1-0.2 \mathrm{sec}^{-1}$, $k^{+}$is about $10^{6} \mathrm{M}^{-1} \mathrm{sec}^{-1}$, and $K_{d}$ is about $100-200 \mathrm{~nm}$ (but see Discussion).

Having obtained a rather crude approximation of the properties of the proposed calcium-binding protein from experimental data on the buildup of PSP enhancement during lowfrequency trains, we can then ask whether or not this constrained model can now predict the relationship between calcium and enhancement during the decay phase following a brief highfrequency stimulus train. As shown in Figure 13, qualitatively
A
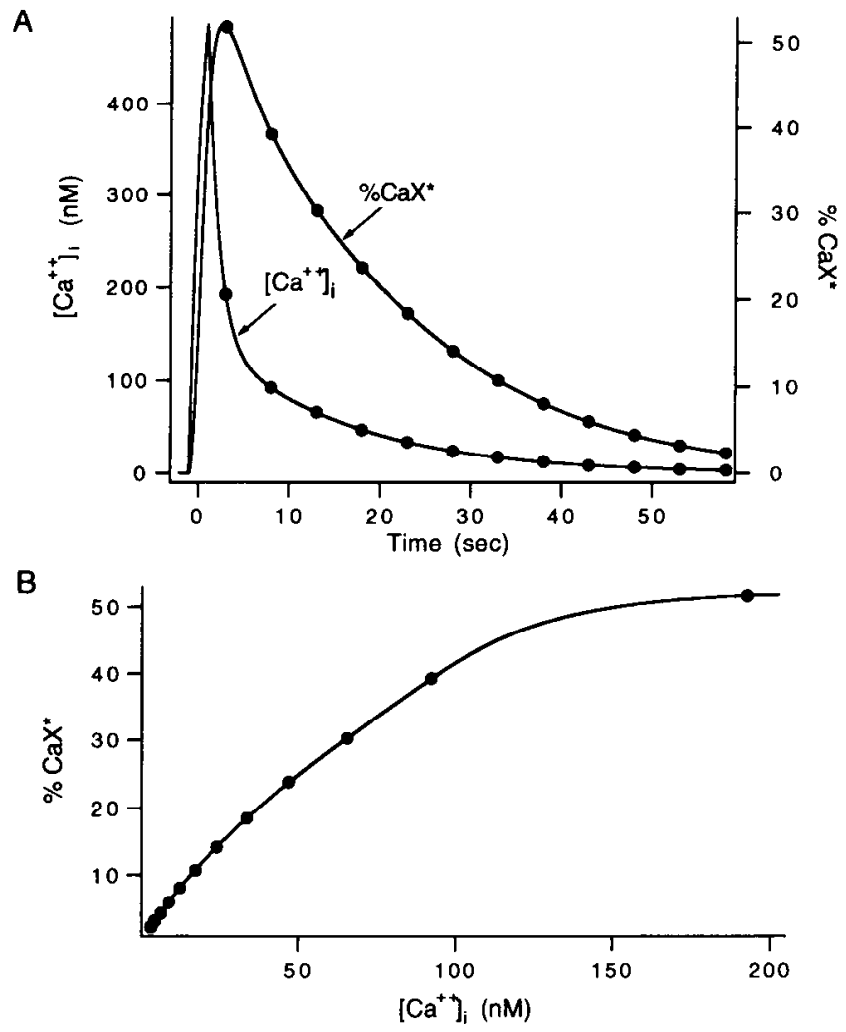

Figure 13. Simulations showing the activation of a calcium binding substrate by imposed calcium transients similar to those produced by brief high-frequency trains. Simulated activation of a calcium binding substrate with an on-rate of $k^{+}=10^{\prime \prime} \mathrm{M}$ ' $\mathrm{sec}$ ' and an off-rate $k=0.2$ sec 1. $A$, Residual calcium transients and activation of substrate. $B$, Percentage of substrate activated as a function of $\Delta\left[\mathrm{Ca}^{2+}\right]$, for $A$.

correct behavior is predicted from the model: $\left[\mathrm{Ca}^{2+}\right]_{i}$ decays more rapidly than the synaptic enhancement, and a plot of enhancement versus calcium level at the same time point is sublinear for the higher calcium concentrations found immediatcly after the decay begins.

\section{Discussion}

The data presented here support the hypothesis that increases in presynaptic residual calcium contribute, through a slow biochemical reaction, to short-term synaptic enhancement at the mossy fiber synapse. Our principal findings are that (1) stimulation of mossy fibers produced $\left[\mathrm{Ca}^{2+}\right]$, transients in associated presynaptic terminals; for low-frequency action-potential trains it was possible to predict the time course of calcium accumulations from the accumulation produced by a brief high-frequency train; (2) changes in $\left[\mathrm{Ca}^{2+}\right]_{i}$ buildup and decay kinetics were associated with concomitant changes in the kinetics of synaptic enhancement, providing strong evidence that $\left[\mathrm{Ca}^{2+}\right]_{t}$ increases caused the enhancement of synaptic strength observed during low-frequency trains and following tetanic stimulation; (3) although a causal relationship is suggested between $\left[\mathrm{Ca}^{2+}\right]_{\text {, }}$ and synaptic enhancement, changes in synaptic strength did not respond instantly to $\left[\mathrm{Ca}^{2+}\right]$, changes; (4) this delayed response was well described by a model that assumes that calcium slowly binds to a substrate that, in turn, increases the probability of release. In the following, we discuss in detail each of these principal findings. 


\section{$\left.\mathrm{Ca}^{2+}\right]_{\mathrm{i}}$ kinetics in mossy fiber presynaptic terminals}

Following single action potentials, $\left[\mathrm{Ca}^{2+}\right]_{i}$ abruptly increased and then decayed exponentially with a time constant $\tau$ of approximately $1 \mathrm{sec}$. We demonstrated that it is possible to use this single action potential calcium transient to predict the calcium accumulations for low-frequency trains of $0.1-2.5 \mathrm{~Hz}$ and for small numbers of action potentials delivered rapidly. The model was presented in Equations 5-8, and it is based on the assumption of linear superposition. For action potentials delivered very rapidly, the peak $\Delta\left[\mathrm{Ca}^{2+}\right]$, produced was then simply a linear function of the number of action potentials and the decay had the same time constant. Experimentally, this simple addition of $\Delta\left[\mathrm{Ca}^{2+}\right]_{i}$ was observed for high-frequency stimulus trains containing up to 10 pulses. For low-frequency trains, the total calcium transient was approximated by the linear superposition of single action potential calcium transients occurring at each action potential time point. In a manner analogous to the buildup of a DC membrane potential from the temporal summing of closely spaced EPSPs, a temporal summation of the transients builds to a steady state plateau value $\left[\mathrm{Ca}^{2+}\right]_{\text {plateau }}$. There is good agreement between the predictions of the linear superposition model and the experimentally observed time course, although there is generally a slight overestimate of $\left[\mathrm{Ca}^{2+}\right]_{\text {plateau. }}$ A particularly important prediction of the linear superposition model, demonstrated in the experimental data shown in Figure $4 D$, is the shape of the $\left[\mathrm{Ca}^{2+}\right]_{\text {plateau }}$ versus frequency curve. This relationship is determined primarily by the time course of calcium decay. Very little calcium accumulation is observed for stimulus frequencies below $(2 \tau)^{-1}$.

The linear superposition model of calcium accumulation is, however, inadequate for prolonged high-frequency trains and for stimulus trains delivered at greater than $2.5 \mathrm{~Hz}$. Furthermore, this model fails to predict the experimentally observed increase in calcium decay time with increasing number of stimulus pulses in high-frequency trains. We suggest several possible explanations of these interesting deviations.

As shown in Figure 3, there is a sublinear relationship between $\Delta\left[\mathrm{Ca}^{2+}\right]$, and the number of spikes in a $100 \mathrm{~Hz}$ train. Thus, during prolonged high-frequency trains, it appears that the calcium transient associated with each action potential decreases. This cannot be explained as a simple calcium buffer effect, since as a buffer becomes more loaded, free calcium increases associated with the next calcium load will increase, not decrease. However, there are a number of other reasons why $\Delta\left[\mathrm{Ca}^{2+}\right]$ might appear to decrease during high-frequency trains. First, the threshold for extracellular afferent fiber stimulation might change, resulting in the failure to generate action potentials. Second, activation of a calcium-activated $K$ channel could narrow the action potential and produce less calcium influx per spike. Third, calcium channels could inactivate through calcium-induced calcium inactivation or other processes (Eckert and Chad, 1984). Fourth, there may be another mechanism for calcium extrusion or sequestration that comes into effect when calcium levels are at the higher levels that are produced by these trains.

Increasing the number of pulses in a stimulus train slowed the decay of calcium. It also slowed the decay of enhancement (see below) and is analogous to the train duration dependence of the rate of decay of PTP observed at other synapses. One possible explanation for this effect is that the rate of calcium extrusion is reduced as the number of action potentials in a train increases. During long high-frequency trains Na levels also build in presynaptic nerve terminals (Delaney and Tank, unpublished observations). Increasing intracellular $\mathrm{Na}$ levels will slow down the rate of calcium extrusion by the $\mathrm{Na} / \mathrm{Ca}$ exchanger. If the $\mathrm{Na} / \mathrm{Ca}$ exchanger is the dominant extrusion mechanism at the mossy fiber synapse, then the time constant of calcium decay will get progressively longer. The role of $\mathrm{Na}$ in PTP has been discussed recently by Mulkey and Zucker for the crayfish neuromuscular junction (1992). A second possible explanation for the prolonged time constant is that a new influx of calcium into the cytoplasm is present following long high-frequency trains. For example, once calcium levels rise above a threshold level, intracellular calcium may be pumped into internal stores that slowly fill. Following train termination, the calcium is slowly released from the stores as the calcium level drops. This new source of calcium influx will prolong the decay of calcium in the terminal. This effect of a slow uptake-slow release mechanism is easily demonstrated in computer models of calcium decay kinetics similar to that introduced by Tank et al. (1991, unpublished observations). This mechanism is particularly appealing since it would also explain the slow creep upward during the "plateau" phase of higher-frequency trains, such as that observed for $5 \mathrm{~Hz}$ stimulation in Figure 4. The creep would occur bccausc intracellular stores would be filling, providing an efflux of calcium from the intracellular space that gets progressively weaker as a level-dependent equilibration is reached between the intracellular calcium and the storage pool.

Lowering the temperature also slowed the decay of calcium under all conditions, with the $Q_{10}$ for the calcium decay time constant in the range of 1.6-1.9. It is possible that the main influence of temperature was to decrease the rate of calcium extrusion.

The time course of calcium increases and decays in mossy fiber terminals appears to be similar to those in terminals at the crayfish neuromuscular junction (Delaney et al., 1989, Delaney and Tank, unpublished observations) and the frog neuromuscular junction (Robitaille and Charlton, 1992). The time constant of calcium decay following a small number of action potentials is $4.2 \mathrm{sec}$ at $18.5^{\circ} \mathrm{C}$ for crayfish (Tank et al., 1991, unpublished observations) compared to $1.1 \mathrm{sec}$ at $32^{\circ} \mathrm{C}$ for mossy fiber terminals.

\section{Increases in $/ \mathrm{C}^{2+} /_{\mathrm{i}}$ contribute to short-term enhancement}

Our experimental results support the hypothesis that increases in $\left[\mathrm{Ca}^{2+}\right]_{i}$ lead to short-term synaptic enhancement at the mossy fiber synapse. First, high-frequency stimulation increased $\left[\mathrm{Ca}^{2+}\right]_{t}$ and enhanced rclcase. Following cessation of stimulation, both calcium and PSP slope decayed back to resting levels, although calcium generally had a more rapid time course than did enhancement. Second, manipulations in the time constant of calcium decay were accompanied by a concomitant change in the kinetics of enhancement. Increasing the number of pulses in the stimulus train, or reducing the temperature increased the decay time of both $\left[\mathrm{Ca}^{2+}\right]_{i}$ and enhancement. Further, for conditions of elevated calcium buffer, produced by the addition of large concentrations of EGTA, $\left[\mathrm{Ca}^{2+}\right]$, and enhancement increased and decayed with identical time courses. Third, during moderate frequency stimulus trains, after calcium and enhancement have plateaued, there is a linear relationship between enhancement and release. Fourth, as shown in Figure $8 B$, the relationship between plateau PSP enhancement and stimulus frequency has a distinctive shape, turning on slowly at low stimulus frequencies 
and then being well approximated by a linear relationship over the range of $0.1-2 \mathrm{~Hz}$. The shape of this curve is predicted by consideration of the calcium kinetics in individual terminals and is well approximated by Equation 8 (compare Fig. $8 B$ for $0.1-2 \mathrm{~Hz}$ with Fig. $4 D$; for stimulus frequencies greater than 2 $\mathrm{Hz}$. PSP it appears that release is saturated.) Thus, the calcium decay time constant, $\tau$, appears to determine the relationship between plateau PSP enhancement and stimulus frequency in the range of $0.1-2 \mathrm{~Hz}$.

\section{Synaptic strength does not respond instantly to changes in residual calcium}

During the onset of action potential trains, $\left[\mathrm{Ca}^{2+}\right]_{i}$ plateaued in about 1 sec while enhancement increased more slowly. After a stimulus train $\left[\mathrm{Ca}^{2+}\right]_{i}$ decayed back to resting levels more rapidly than did enhancement. There was typically a difference of 5-10 sec in the time constant of decay at $32^{\circ} \mathrm{C}$, and this difference became more apparent at lower temperatures.

We presented a kinetic model that provides one possible explanation for the delay between calcium increases and synaptic enhancement. The model assumes that enhancement is driven by a calcium-dependent reaction. During a moderate frequency stimulus train the buildup of enhancement is primarily determined by the kinetics of the calcium-driven reaction. At higher stimulus frequencies enhancement builds more rapidly because at higher calcium concentrations in the presynaptic terminal, the reaction product, $\mathrm{CaX}^{*}$, is produced more rapidly. For the simplified case of an instantaneous calcium step a delayed response similar to that observed experimentally is easily demonstrated analytically, as shown in Equations 12-14 and numerically simulated in Figure 12. Consistent with our model, slowing of calcium kinetics with EGT $\Lambda$ eliminates the temporal delay in the expression of enhancement.

Our kinetic model suggests that for the decay phase of PTP the time course of enhancement at the mossy fiber synapse is determined in part by the calcium decay kinetics and in part by the slower kinetics of the calcium-driven reaction. The relative contribution of these factors is temperature dependent: at low temperatures the kinetics of the reaction binding site dominate and enhancement is slowed more relative to the calcium decay. At high temperatures calcium kinetics play a more important role and the difference in time constant between calcium decay and the decay of enhancement is reduced.

It is interesting to compare our model with that of Magleby and colleagues (summarized in Magleby, 1987) to account for enhancement during and following high-frequency trains. Our experiments predict that for a brief train the component of enhancement studied here will not peak instantly, as in the models proposed by Magleby and colleagues, but will instead peak with a delay after the train has terminated. Nonetheless, our observations are still consistent with their experiments. Following a high-frequency train, fast components of enhancement (such as F1, F2) would obscure such a delay in slower components of enhancement (such as augmentation and PTP).

We have provided estimates of the kinetic properties of the calcium-driven reaction $\left(k \approx 0.1-0.2 \mathrm{sec}^{-1}, k^{+} \approx 10^{6} \mathrm{M}^{-1}\right.$ $\sec ^{-1}$, and $K_{d} \approx 100-200 \mathrm{~nm}$ ). The off-rate for this reaction is sufficiently slow that this site is unlikely to be involved in either F1 or F2, two forms of short-term facilitation that have time constants of decay of about $50 \mathrm{msec}$ and $500 \mathrm{msec}$ at the mossy fiber synapse (Regehr, Delaney, and Tank, unpublished obser- vations). This is apparent from consideration of the case in which a very large brief pulse of calcium activates the binding site. The reaction product would decay with a time constant of $\left(k^{-}\right)^{-1} \approx 5-10 \mathrm{sec}$. With regard to $k^{+}$and $K_{d}$, it must be remembered that our estimates depend upon $\Delta\left[\mathrm{Ca}^{2+}\right]_{i}$, which in turn depends upon the properties of fura- 2 within the presynaptic terminal.

It is unlikely that other forms of use-dependent modification, such as short-term facilitation and depression, could interfere with our study of the enhancement that occurs on the tens of seconds time scale. F1 and F2 and produce very little enhancement even for $5 \mathrm{~Hz}$ stimulation. Although synaptic depression is present at this synapse, particularly at lower temperatures, we do not feel it contributes significantly to the delay between changes in calcium and enhancement, because no depression occurs at the onset of a stimulus train where a delay is nevertheless observed. However, further experiments are necessary to rule out completely a contribution of depression to the delay that is observed in the decay phase following an action potential train.

It is worth emphasizing that most of the conclusions we draw do not depend upon a precise measurement of the resting calcium concentration, or upon the absolute calcium concentration. We have been primarily concerned with comparing the time course of calcium transients with that of synaptic enhancement. However, quantification of calcium is an important issue when considering the model we have proposed. Using a fura-2 dissociation constant of $200 \mathrm{~nm}$ and a viscosity correction factor of 0.7 to estimate $\left[\mathrm{Ca}^{2+}\right.$ ], (Poenie et al., 1986; Regehr and Tank, 1992), then an increase in $\left[\mathrm{Ca}^{2+}\right]$, from a resting level of $50 \mathrm{~nm}$ to 70 nM produces about a twofold synaptic enhancement. If, as we propose in our model, calcium is driven by a first-order calcium-dependent reaction, how can a $40 \%$ increase in $\left[\mathrm{Ca}^{2+}\right]$, produce a $100 \%$ enhancement of release? This may simply reflect the use of incorrect parameters to determine resting calcium. Another possibility is that this form of enhancement is sensitive to $\Delta\left[\mathrm{Ca}^{2+}\right]_{i}$ and not to $\left[\mathrm{Ca}^{2+}\right]_{i}$ (i.e., that the system adapts to the resting calcium concentration).

\section{Biophysical models of the calcium-dependent enhancement}

There are a multitude of potential sites at which calcium might act to enhance release (Almers and Tse, 1990; Linstedt and Kelly, 1991; Petrenko et al., 1991; Sudhof and Jahn, 1991; Thomas and Almers, 1992). We will explore two candidate sites in more detail: (1) direct binding to a site on the postulated vesicle fusion protein and (2) binding to a protein such as calmodulin that initiates a biochemical cascade that alters vesicle availability.

It is widely thought that calcium triggers neurotransmitter release by interacting with a protein that promotes membrane vesicle fusion (Almers and Tse, 1990). Although the fusion protein has not as yet been identified, it must be located in close proximity to the vesicle and to the membrane. It is thought that there are multiple calcium binding sites and at least one of the binding sites would need to be low affnity $\left(K_{d}>10 \mu \mathrm{M}\right)$ to account for the high calcium levels needed to trigger vesicle fusion. It is possible that the calcium binding site responsible for short-term synaptic enhancement on the tens of seconds time scale is also located on the fusion protein. Such an enhancement site would be exposed to the very high, brief, calcium transient that occurs during an action potential. An important 
question that arises is whether or not this exposure would always saturate the enhancement site, which would be inconsistent with experiment.

Although the instantaneous calcium concentration at the fusion protein during release is much higher than $\left[\mathrm{Ca}^{2+}\right]_{i}$ measured during PTP, it does not follow that activation of the enhancement site would be large. Following an action potential, the binding to such a site would be dominated by the on-rate, the affinity is irrelevant. Given the estimates of the kinetic constants for the enhancement site that we have determined from our experiments, the fractional change in enhancement produced by a single action potential would be approximately

$$
\begin{aligned}
\frac{\Delta\left[\mathrm{CaX}^{*}\right]}{[X]} & \approx k^{\prime}\left[\mathrm{Ca}^{2+}\right] \Delta t \\
& =\left(10^{6} \mathrm{M}^{-1} \mathrm{sec}{ }^{\prime}\right)(50 \mu \mathrm{M})(1 \mathrm{msec})=0.05
\end{aligned}
$$

An action potential would only activate $5 \%$ of the sites, due to the slow on-rate, so saturation of the site is not a potential problem with this biophysical model. Thus, the hypothesis that a fusion protein contains multiple binding sites, one of which enhances the release process through a calcium-dependent reaction with slow kinctics, is consistent with the experiments we have described here.

A second possibility is that $\left[\mathrm{Ca}^{2+}\right]$, may act as a second messenger at a site distinct from the fusion protein to enhance release. An example of such a process is that proposed by Llinas and Greengard (Llinas et al., 1991). According to this scheme, a pool of vesicles is normally tethered to cytoskeletal elements by unphosphorylated synapsin and is unavailable for release. Calcium increases that, through calmodulin, activate $\mathrm{CaM} \mathrm{ki-}$ nase II and phosphorylate synapsin release tethered vesicles and make them available to bind to the release site, producing a greater release probability to subsequent action potentials. For this scheme to be responsible for short-term enhancement at mossy fiber terminals, the calcium dependence of the reaction would need to be the rate-limiting step. This implies that there would have to be a binding site on calmodulin with the appropriate forward and reverse rate constants, with the dependence of activation on calcium concentration approximately linear for calcium elevations of order $100 \mathrm{~nm}$. One clear prediction is that blocking calmodulin should block short-term enhancement. Although the effects of calmidozolium have been examined at the CA3-to-CA 1 pyramidal cell synapse, the experiments employed high-frequency tetanic stimulation to induce long-term potentiation (LTP) and did not explore the question of calmodulin's role during low-frequency stimulation.

Other models that propose calcium-mediated biochemistry distinct from that underlying vesicle release have recently been proposed for the crab T-fiber giant synapse (Lin and Llinas, 1992), and release from chromaffin cells (Heinemann et al., 1992), and have been considered for facilitation (Stanley, 1986; Yamada and Zucker, 1992). For chromaffin cells, measurements of calcium and release are well explained by assuming that there are two populations of vesicles: one available for immediate release and another that is not. Augmentation of release is accomplished by calcium acting at locations distinct from the release site to convert vesicles into the state available for release. Although calcium has not been measured in the crab T-fiber giant synapse, a similar mechanism has been proposed for tonic transmitter release and potentiation.
Comparison of the role of calcium in short-term plasticity at the mossy fiber synapse and at the crayfish neuromuscular junction

At the crayfish neuromuscular junction, increases in $\left[\mathrm{Ca}^{2+}\right]_{1}$ produce augmentation and PTP. Although for technical reasons we have not yet demonstrated the sufficiency of calcium increases produced independent of action potential-induced influx to cause enhancement at the mossy fiber synapse, nevertheless, our experiments suggest that the short-term enhancement observed both during and following action potential trains is also caused by the second messenger actions of $\left[\mathrm{Ca}^{2+}\right]_{i}$. Although many of the basic features of calcium-induced enhancement are similar at these two synapses, there are interesting differences.

At the crayfish neuromuscular junction enhancement responds rapidly to changes in $\left[\mathrm{Ca}^{2+}\right]_{i}$, while at the mossy fiber synapse there is a delay. At present, our working hypothesis is that this delay is produced by the relatively slow kinetics of a calcium-activated reaction that drives the enhancement. We suggest that the enhancement observed at the crayfish neuromuscular junction is also driven by a similar calcium-dependent reaction with slightly more rapid kinetics. Enhancement at mossy fiber synapses is determined in part by the kinetics of the underlying reaction and in part by the calcium dynamics. In contrast, at the crayfish neuromuscular junction the time course of synaptic enhancement is determined primarily by calcium dynamics, since enhancement responds rapidly to changes in calcium. It also appears that synaptic enhancement is much more sensitive to $\left[\mathrm{Ca}^{2+}\right]_{i}$ at mossy fiber synapses than at the crayfish neuromuscular junction. The degree to which enhancement at these two synapses shares the same biochemical machinery is not known. An appealing possibility is that the processes are fundamentally very similar, differing only in the kinetics of the reaction. To account for the rapid response of calcium and the linear relationship between calcium and release, even when calcium levels are quite high, the properties of the calcium binding site for the crayfish neuromuscular junction would need to have $k^{+}>2 \times 10^{6} \mathrm{M}^{-1} \mathrm{sec}^{-1}, K_{d}>2 \mu \mathrm{M}$, and $k>1 \mathrm{sec}$ '. As attractive as this hypothesis may be, it is still very speculative; it may also be true that calcium acts through fundamentally different biochemical pathways at these two synapses.

\section{Short-term use-dependent enhancement of synaptic strength in the CNS}

Given that the firing rates of dentate granule cells in behaving rodents are in the frequency ranges we have used for stimulus trains in our experiments, the synaptic enhancement mechanism we have described is likely to be operational in vivo (Buzsaki and Czeh, 1992). The use-dependent enhancement at mossy fibers has many similarities to that exhibited at the crayfish neuromuscular junction. That two synapses in such different animals exhibit similar forms of short-term synaptic plasticity suggests that the biophysical mechanisms that are embodied in the calcium-dependent enhancement may be a universal property found in many types of synapses. We suggest that selective tuning of the kinetic rate constants at different synapses provides the biophysical mechanism by which functionally different shortterm synaptic memory requirements are satisfied.

\section{References}

Adler EM, Augustine GJ, Duffy SN, Charlton MP (1991) Alien intracellular calcium chelators attenuate neurotransmitter release at the squid giant synapse. J Neurosci 11:1496-1507. 
Almers W, Tse FW (1990) Transmitter release from synapses: does a preassembled fusion pore initiate exocytosis? Neuron 4:813-818.

Amaral DG (1979) Synaptic extensions from mossy fibers of the fasia dentata. Anat Embryol (Berl) 155:241-251.

Atwood HL, Wojtowicz JM (1986) Short-term and long-term plasticity and physiological differentiation of crustacean motor synapses. Int Rev Neurobiol 28:275-362.

Augustine G (1990) Regulation of transmitter release at the squid giant synapse by presynaptic delayed rectifier potassium current. J Physiol (Lond) 431:343-364.

Buzsaki G, Czeh G (1992) Physiological function of granule cells: a hypothesis. Epilepsy Res [Suppl] 7:281-290.

Charlton MP, Smith SJ, Zucker RS (1982) Role of presynaptic calcium ions and channels in synaptic facilitation and depression at the squid giant synapse. J Physiol (Lond) 323:173-193.

Claiborne BJ, Amaral DG, Cowan WM (1986) A light and electron microscopic analysis of the mossy fibers of the rat dentate gyrus. $J$ Comp Neurol 246:435-458.

Cohen MW, Jones OT, Angelides KJ (1991) Distribution of $\mathrm{Ca}^{2+}$ channcls on frog motor nerve terminals revealed by fluorescent $\omega$-conotoxin. J Neurosci 11:1032-1039.

Connor JA, Kretz. R, Shapiro E (1986) Calcium levels measured in presynaptic neurone of Aplysia under conditions that modulate transmitter release. J Physiol (Lond) 375:625-642.

Delaney KR, Zucker RS, Tank DW (1989) Calcium in motor nerve terminals associated with posttetanic potentiation. J Neurosci 9:35583567 .

Delaney KR, Regehr WG, Tank DW (1991) Residual calcium and enhancement of transmitter release: evidence from invertebrate and vertebrate synapses for causality and universality. Soc Neurosci Abstr 17:577.

Delaney KR, Tank DW (1994) A quantitative measure of the dependence of short-term synaptic enhancement on presynaptic residual calcium. J Neurosci, in press.

Eckert R, Chad JE (1984) Inactivation of calcium channels. Prog Biophys Mol Biol 44:215-267.

Griffith WH (1990) Voltage-clamp analysis of postletanic potentiation of the mossy fiber to CA3 synapse in hippocampus. J Neurophysiol 63:491-501.

Grynkiewicz G, Poenie M, Tsien RY (1985) A new generation of $\mathrm{Ca}^{2+}$ indicators with greatly improved fluorescence properties. J Biol Chem 260:3440-3450.

Harkins AB, Kurebayashi N, Baylor SM (1993) Use of fluo-3 to estimate resting myoplasmic free calcium in frog skeletal muscle fibers. Biophys $\mathrm{J}$, in press.

Heinemann C, Ruden LV, Chow RH, Neher E (1992) A two-step model for secretory control in neuroendocrine cells. Soc Neurosci Abstr 18:635.

Katz B, Miledi R (1967) The timing of calcium action during neuromuscular transmission. J Physiol (Lond) 189:535-544.

Katz. B, Miledi R (1968) The role of calcium in neuromuscular facilitation. J Physiol (Lond) 203:459-487.

Konishi M, Olson S, Hollingworth S, Baylor SM (1988) Myoplasmic binding of fura- 2 investigated by steady-state fluorescence and absorbance measurements. Biophys J 54:1089-1 104

Kretz R, Shapiro E, Kandel ER (1982) Post-tetanic potentiation at an identified synapse in Aplysia is correlated with $\mathrm{Ca}^{2+}$-activated $\mathrm{K}^{+}$ current in the presynaptic neuron: evidence for calcium accumulation. Proc Natl Acad Sci USA 79:5430-5434.

Lin J-W, Llinas R (1992) Depolarization-activated potentiation of the T-fiber synapse in the blue crab. J Gen Physiol 101:45-65.

Linstedt AD, Kelly RB (1991) Molecular architecture of the nerve terminal. Curr Opin Neurobiol 1991:382-387.

Llinas R, Gruner JA, Sugimori M, McGinness TL, Greengard P (1991) Regulation by synapsin I and $\mathrm{Ca}^{2+}$-calmodulin-dependent protein kinase of transmitter release in squid giant synapse. J Physiol (Lond) 436:257-282.

Magleby KL (1987) Short-term changes in synaptic efficacy. In: Synaptic function (Edelman GM, Gall WE, Cowan WM, eds), pp 21-56. New York: Wiley.

McNaughton BL (1982) Long-term synaptic enhancement and shortterm potentiation in rat fascia dentata act through different mechanisms. J Physiol (Lond) 324:249-262.
Mulkey RM, Zucker RS (1992) Posttetanic potentiation at the crayfish neuromuscular junction is dependent on both intracellular calcium and sodium ion accumulation. J Neurosci 12:4327-4336.

Neher E, Augustine GJ (1992) Calcium gradients and buffers in bovine chromaffin cells. J Physiol (Lond) 450:273-301.

Neisen C, Charlton MP, Carlen PL (1991) Postsynaptic and presynaptic effects of the calcium chelator BAPTA on synaptic transmission in rat hippocampal dentate granule cells. Brain Res 555:319-325.

Petrenko AG, Perin MS, Davletov BA, Ushkaryov YA, Geppert M, Sudhof TC (1991) Binding of synaptotagmin to the $\alpha$-latrotoxin receptor implicates both ion synaptic vesicle exocytosis. Nature 353: 65-68.

Poenie M, Alderton J, Steinhardt R, Tsien R (1986) Calcium rises abruptly and briefly throughout the cell at the onset of anaphase. Science 233:886-889.

Regehr WG, Tank DW (1991a) The maintenance of LTP at hippocampal mossy fiber synapses is independent of sustained presynaptic calcium. Neuron 7:451-459.

Regehr WG, Tank DW (1991b) The role of calcium in synaptic plasticity at the hippocampal mossy fiber synapse. Soc Neurosci Abstr $17: 577$.

Regehr WG, Tank DW (1991c) Selective fura-2 loading of presynaptic terminals and nerve cell processes by local perfusion in mammalian brain slice. J Neurosci Methods 37:111-119.

Regehr WG, Tank DW (1992) Calcium concentration dynamics produced by synaptic activation of CAl hippocampal pyramidal cells. J Neurosci 12:4202-4223.

Regehr WG, Delaney KR, Tank DW (1992) Presynaptic calcium and short term synaptic enhancement at hippocampal mossy fiber synapses: experiments and kinetic modelling. Soc Neurosci Abstr 18: 245

Roberts WM, Jacobs RA, Hudspeth AJ (1990) Colocalization of ion channels involved in frequency selectivity and synaptic transmission at presynaptic active zones of hair cells. J Neurosci 10:3664-3684.

Robitaille R, Charlton MP (1992) Presynaptic calcium signals and transmitter release are modulated by calcium-activated potassium channels. J Neurosci 12:297-305.

Robitaille R, Adler EM, Charlton MP (1990) Strategic location of calcium channels at transmitter sites of frog neuromuscular synapses. Neuron 5:773-779.

Simon SM, Llinas RR (1985) Compartmentalization of the submembrane calcium activity during calcium influx and its significance in transmitter release. Biophys J 48:485-498.

Stanley EF (1986) Decline in calcium cooperativity as the basis of facilitation at the squid giant synapse. J Neurosci 6:782-789.

Sudhof TC, Jahn R (1991) Proteins of synaptic vesicles involved in exocytosis and membrane recycling. Neuron 6:665-677.

Swandula D, Hans M, Zipser K, Augustine GJ (1991) Role of residual calcium in synaptic depression and posttetanic potentiation: fast and slow calcium signaling in nerve terminals. Neuron 7:915-926.

Tank DW, Regehr WG, Delaney KR (1991) Modeling a synaptic chemical computation: the buildup and decay of presynaptic calcium. Soc Neurosci Abstr 17:578.

Thomas P, Almers W (1992) Exocytosis and its control at the synapse. Curr Opin Neurobiol 2:308-311.

Yamada WM, Zucker RS (1992) Time course of transmitter release calculated from simulations of a calcium diffusion model. Biophys $\mathrm{J}$ $7: 671-682$

Zar JH (1974) Biostatistical analysis. Englewood, NJ: Prentice Hall.

Zengel JE, Magleby KL, Horn JP, McAfee DA, Yarowsky PJ (1980) Facilitation, augmentation, and potentiation of synaptic transmission at the superior cervical ganglion of the rabbit. J Gen Physiol 76:213231.

Zucker RS (1988) Frequency dependent changes in excitatory synaptic efficacy. In: Mechanisms of epileptogenesis (Dichter MA, ed), pp 153167. New York: Plenum.

Zucker RS, Delaney KR, Mulkey R, Tank DW (1991) Presynaptic calcium in transmitter release and posttetanic potentiation. In: Calcium entry and action at the presynaptic terminal (Stanley EF, Nowycky MC. Triggle DI, eds), pp 191-207. New York: New York Academy of Sciences. 